\title{
Sources of Mistrust: An Experimental Case Study of a Central Asian Water Conflict
}

\author{
Klaus Abbink · Lars Christian Moller • Sarah O'Hara
}

Accepted: 23 July 2009 / Published online: 15 August 2009

(C) The Author(s) 2009. This article is published with open access at Springerlink.com

\begin{abstract}
With the disintegration of the USSR a conflict arose between Kyrgyzstan, Uzbekistan and Kazakhstan over the transboundary Syr Darya river. Upstream Kyrgyzstan controls the Toktogul reservoir which generates hydropower demanded mainly in winter for heating. Downstream Uzbekistan and Kazakhstan need irrigation water in summer, primarily to grow an export crop (cotton). Regional agreements obliging Kyrgyzstan to higher summer discharges in exchange for fossil fuel transfers from downstream riparians in winter have been unsuccessful, due to lack of trust between the parties. Striving for self-sufficiency in irrigation water, Uzbekistan initiated new reservoir construction. This paper examines their economic impact. We report a laboratory experiment modelling the Syr Darya scenario as a multi-round, three-player trust game with non-binding contracts. Payoff schemes are estimated using real-life data. While basinwide efficiency maximisation requires regional cooperation, our results demonstrate that cooperation in the laboratory is hard to achieve. Uzbek reservoirs improve cooperation only weakly and their positive impact is limited to low-water years.
\end{abstract}

Disclaimer The findings, interpretations, and conclusions expressed in this paper are entirely those of the authors. They do not necessarily represent the views of the International Bank for Reconstruction and Development/World Bank and its affiliated organizations, or those of the Executive Directors of the World Bank or the governments they represent .

K. Abbink $(\bowtie)$

CREED, Faculty of Economics and Econometrics, University of Amsterdam, Roetersstraat 11, 1018WB Amsterdam, The Netherlands

e-mail: k.abbink@uva.nl

L. C. Moller

World Bank, 1818 H Street N.W., Washington, DC 20433, USA

e-mail: 1moller@worldbank.org

S. O’Hara

School of Geography, The University of Nottingham, University Park, Nottingham NG7 2RD, UK

e-mail: sarah.o'hara@nottingham.ac.uk 
Keywords Central Asia - Common-pool resources - Dams - Hydropower - Irrigation · Experimental economics $\cdot$ Regional public goods $\cdot$ Syr Darya $\cdot$ Trust games $\cdot$ Water

\section{JEL Classification $\quad \mathrm{C} 72 \cdot \mathrm{C} 92 \cdot \mathrm{O} 53 \cdot \mathrm{Q} 25$}

\section{Introduction}

The collapse of the Soviet Union in 1991 left the newly independent Central Asian Republics with a difficult transition task and inter-state relations that have not always been easy. Almost immediately a conflict arose over the use and allocation of the waters of the Syr Darya river with major economic and political ramifications for the region. Upstream Kyrgyzstan operates the sizable Toktogul Reservoir to facilitate hydropower production while the downstream riparians, Uzbekistan and Kazakhstan, divert water from the river to irrigate land dominated by cotton cultivation. ${ }^{1}$ The conflict stems from the diametrically opposed seasonal requirements for water in the different countries. Kyrgyzstan has the highest demand for electricity in the winter months thus generating an incentive to store summer inflows into the Toktogul Reservoir for subsequent release during the winter. In contrast, the downstream countries require water to be released during the summer months to irrigate their agricultural lands, but have no use for the water in winter.

The different seasonal water requirements of the upstream and downstream republics have long been problematic. During the Soviet period the decision on when and how much water was to be released from the upstream reservoir was made by central planners in Moscow. For years Kyrgyzstan was ordered to discharge water during the summer so that the cotton fields of Uzbekistan and Kazakhstan could be irrigated. In exchange the downstream countries sent electric power, coal and gas to Kyrgyzstan during the winter months. With Moscow no longer intervening in such matters the riparian states were forced to seek voluntary cooperative agreements over water and energy. However, barter agreements that obliged Kyrgyzstan to operate the reservoir in an irrigation mode, in exchange for coal and gas supplies from Uzbekistan and Kazakhstan during the winter months, were invariably breached by all three parties. A fundamental lack of trust has been central to the failure of interstate agreements and although a co-operative agreement could be beneficial for all three countries, it has proven prohibitively hard to implement one in practice.

Frustrated by the history of failed agreements the downstream countries are increasingly leaning towards a policy of self-sufficiency, making themselves less dependent on Kyrgyzstan. To this end, Uzbekistan has pursued plans to construct new reservoirs on its territory. The reservoirs will store upstream winter releases for irrigation use in summer. But to what extent do these new reservoirs represent the long-awaited solution to the conflict? Several issues need to be addressed to answer this question. First, the fact that the cooperation record has been poor so far does not imply that this will be the case in the future. The 2005 revolution in Kyrgyzstan and the forthcoming retirement of senior government officials in all the riparian states bring new players to the negotiation table. ${ }^{2}$ It is possible that new players will act differently, making expensive reservoir construction obsolete. So the question arises whether the previous failure to cooperate is systematic or idiosyncratic. In other words, has cooperation failed because this is inherent to the problem, or because the decision makers in charge have been incapable of working together? Secondly, the capacity of the new down-

1 Kazakhstan is located downstream to Uzbekistan.

2 Many of the most senior officials in the water sector are near or have passed the official age of retirement. 
stream reservoirs is limited. While they mitigate the costs of uncoordinated behaviour, they do not eliminate the need for cooperation to maximise basinwide efficiency. If incentives to cooperate get even worse, not much may be gained.

The aim of this paper is to address these questions. We designed a model that estimates the economic impact of the new reservoirs on the riparian economies. In doing so we had to tackle two difficulties. First, the model needs to trace the real economic situation as accurately as possible, despite notoriously limited data availability. We collated data from a variety of sources and from a series of interviews with experts on location-government officials and representatives of development agencies - to make estimates as informed as possible. Secondly, costs and benefits from the new reservoirs crucially depend on the ability of decision makers to cooperate, which is a behavioural issue. To examine this, we introduce a novel approach to the analysis of transboundary river conflicts. We used a model estimated from real data and designed a game that resembles the strategic environment in the Syr Darya river conflict. Controlled laboratory experiments were then conducted to study the likelihood of future cooperation. Building on a long tradition of experimental research the laboratory appears to be an ideal testbed to study scenarios of cooperation and conflict in shared river basins. We re-create an analogous, although stylised, set of conditions where we can analyse the strategic environment of the Syr Darya conflict in different future scenarios. In four separate treatments, we simulate the economic scenario with and without the new Uzbek reservoirs under three representative hydrological regimes.

We find that Uzbek reservoirs do not represent the solution to the river conflict. Maximisation of basinwide efficiency continues to require riparian cooperation. Though they alleviate Uzbekistan's problems in low-water years the reservoirs are not sufficiently large to achieve Uzbek self-sufficiency in irrigation water. Moreover, the experimental results reveal that cooperation is indeed very hard to establish in the present strategic environment, especially in low-water years. Contracts are frequently broken-so frequently that they do not improve efficiency over a control scenario without any agreements. Thus failure to cooperate should not solely be attributed to the unwillingness or incapability of current decision makers, but, as we argue, to the inherit coordination problem that the riparians are trying to solve. Finally, we find that reservoirs improve the likelihood of cooperation only marginally.

The remainder of this paper is organised as follows: Sect. 2 provides background information on the river conflict and reviews relevant literature. Section 3 develops the model and describes the experimental design. Section 4 presents the experimental results. Section 5 summarises and concludes.

\section{Background $^{3}$}

Water resources are of critical importance to the Central Asian economies. ${ }^{4}$ Mountainous Kyrgyzstan has a substantial hydropower potential covering up to $80 \%$ of its domestic energy needs. Hydropower exports - through barter trade to other Central Asian countries and to Russia in cash-account for approximately $10 \%$ of total exports. In Uzbekistan, irrigated

\footnotetext{
${ }^{3}$ For further information see Economist Intelligence Unit (2004), International Monetary Fund (2008), Linn et al. (2005), O'Hara (2000a,b), SPECA (2004), US Department of Agriculture (2004) and World Bank (2004a, b, c, d, e).

4 With a GDP of US $\$ 3.5 \mathrm{bn}$. and a population of $5.2 \mathrm{~m}$, Kyrgyzstan is one of the poorest countries in the region. Uzbekistan is larger and slightly less poor. It has a GDP of US $\$ 22.3 \mathrm{bn}$. and a population of $26.9 \mathrm{~m}$. Kazakhstan is the most prosperous country in a poor region. Its GDP is US $\$ 103.8 \mathrm{bn}$. in a population of $15.5 \mathrm{~m}$ (2007 data).
} 


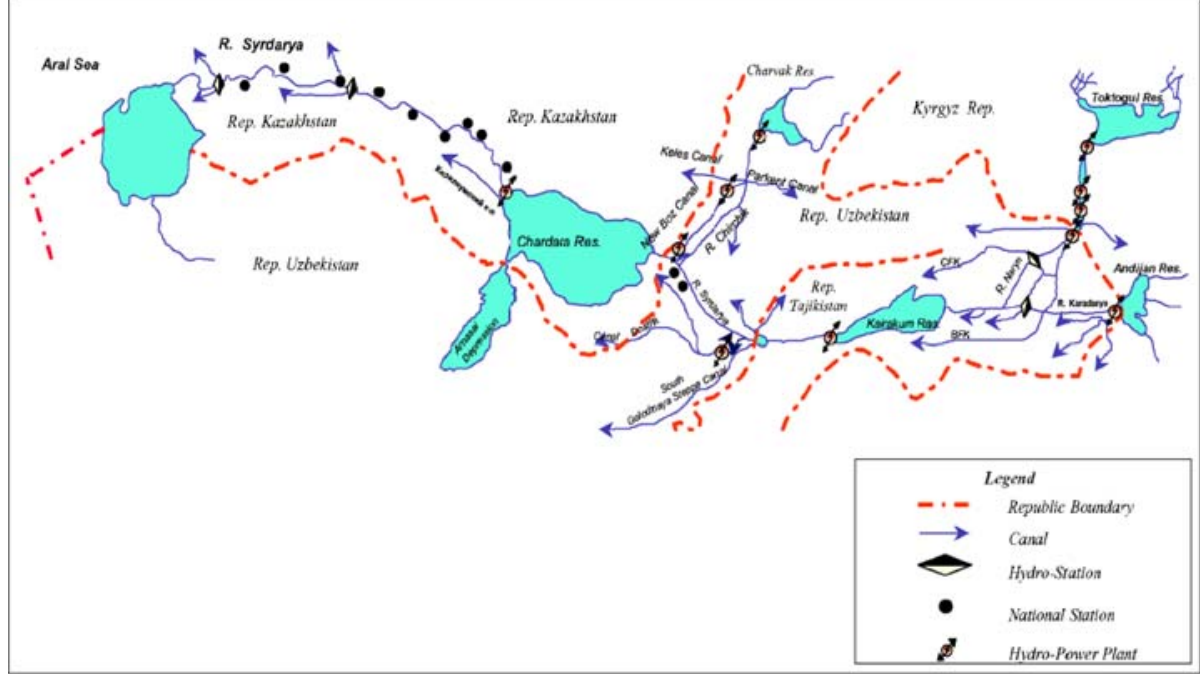

Fig. 1 Map of the Syr Darya river. Note: Map not drawn to scale. Source: World Bank (2004a)

cotton production is the most important economic activity in an agriculturally dominated economy. The country is the World's second largest cotton exporter with a market share of almost $10 \%$. Cotton exports totalled US $\$ 1.1$ billion in 2007, equivalent to $14 \%$ of total commodity exports. Finally, although the Syr Darya is of relatively low economic significance to the oil-dominated Kazakh economy, it is nevertheless of substantial regional importance. Cotton exports from South-Kazakhstan (one of the two provinces that the Syr Darya flows through) equalled around 1\% of total Kazakh exports in 2002.

The Syr Darya, one of Central Asia's most important transboundary rivers, rises in the mountains of Kyrgyzstan. It has two main tributaries, the Naryn and the Kara Darya which merge in eastern Uzbekistan to form the Syr Darya proper. From there the river flows into Tajikistan $^{5}$ before re-entering Uzbekistan and finally flowing into Kazakhstan where it discharges into the remnants of the Small Aral Sea (see Fig. 1). ${ }^{6}$ The flows of the Syr Darya and its tributaries are regulated by a series of reservoirs built during the Soviet period. The most important of these being the substantial, multi-purpose Toktogul Reservoir (14.5 billion cubic meters, BCM) built in the 1970s on the Naryn River in Kyrgyzstan. The reservoir was primary constructed to even out inter-annual variations in river flows thereby maximising its irrigation potential. Toktogul is also used to produce hydropower.

Under Soviet administration Toktogul was operated under an irrigation regime whereby $75 \%$ of the annual discharge was released from the reservoir in the summer months (April-September). Releases during the winter months (October-March) accounted for the remaining 25\%. Surplus hydropower, in excess of Kyrgyz demand, generated in the summer was fed into the Central Asian Power System for use by the Uzbek and southern Kazakh regions. Since the Kyrgyz region lacked any significant fossil fuel resources, they were trans-

5 Tajikistan plays only a minor, regulatory role on the Syr Darya due to its relatively low reservoir storage capacity and insignificant irrigation withdrawal rates. For this reason Tajikistan is not treated explicitly in this analysis.

6 The tragedy of the shrinking Aral Sea is a disastrous side effect of intensive irrigation. This issue is outside the scope of our study. 
ferred from the Uzbek and Kazakh republics to enable the Kyrgyz region to meet its winter demand for electricity and heat through thermal energy production.

After independence, the Soviet arrangement came under great strain. Fossil fuel prices rose quickly to world price levels and payments were increasingly demanded in hard currency. Households in Kyrgyzstan switched from expensive fossil fuel fired heating to electric heating, thus increasing winter electricity demand. Kyrgyzstan could not afford to import fossil fuels to generate electricity and started to increase winter discharges of water from Toktogul to meet its winter power demand and reduce summer releases to store water for the following winter. As a result, farmers in Uzbekistan and Kazakhstan faced irrigation water shortages in summer. Furthermore, the frozen waterways and canals were unable to handle the larger volume of water in winter, occasionally causing flooding on downstream territories.

In the absence of a central planner to solve this conflict, the newly independent republics had to seek voluntary cooperative agreements. In February 1992 they signed the Almaty Agreement agreeing to the joint ownership and management of the region's water resources, while retaining sovereign control over crops, industrial goods and electric power obtained from them. The agreement further reiterated the need for cooperation. But this, as well as annual agreements for the release of water and exchange of electricity and fossil fuels, proved ineffective and could not arrest the increasing orientation towards power production of the Toktogul operation. Eventually in March 1998, Kazakhstan, Kyrgyzstan and Uzbekistan entered into a Long Term Framework Agreement which explicitly recognised that annual and multi-year irrigation water storage has a cost and that it needs to be compensated, either through a barter exchange of electricity and fossil fuels or in cash. But, the supply of fossil fuels generally fell short of agreed quantities and quality, forcing Kyrgyzstan to increase winter discharges. In wet years downstream states did not need the agreed volumes of summer discharges and this affected the export of electricity and the compensating quantities of fossil fuel transfers to Kyrgyzstan. The latter was thus exposed to a serious risk in meeting its winter demand for heating and power. To reduce this risk, Kyrgyzstan, on average, reduced summer releases to $45 \%$ of the annual discharges (and winter releases increased to $55 \%$ ) during the 1990s.

When matters failed to improve in the new millennium, the Uzbek position changed towards a decisive unilateral stance. The most explicit expression hereof has been the decision to construct a series of re-regulating reservoirs. Uzbekistan proceeded with the design of new water storage capacity of about 2.5 BCM. The impact of the Uzbek decision has been substantial for Kyrgyzstan and Kazakhstan. The Kyrgyz challenge is that even when operated in the noncooperative 'power mode', production is insufficient to cover domestic winter electricity demand. In the absence of a regional agreement, the Kyrgyz government must aim to cover this deficit through a combination of domestic reforms and construction of new power-generating facilities - both of which represent daunting challenges. Kazakhstan, which had otherwise pursued a cooperative strategy towards Kyrgyzstan, has had to come to terms with the fact that this strategy ultimately depended on Uzbek willingness to cooperate. Since the latter was not forthcoming, Kazakhstan has also shown renewed interest in the construction of re-regulating reservoirs on its own territory. Plans exist for constructing a 3 BCM Kazakh reservoir, although no final political decision has been made to initiate construction. $^{7}$

The central problem for the interstate agreements has been one of trust. Short of military action there are no means to enforce a contract between sovereign republics who are generally suspicious of each other. If Kyrgyzstan discharges additional water in summer, it must

7 Personal communication with Leonid Dmitriev, Kazgiprovodhoz, Almaty (15 December 2004). 
trust the downstream riparians to deliver fossil fuels in winter, otherwise it will face a severe problem of not being able to meet its winter energy demand. Hence, it must incur a temporary economic loss and would rely on compensation from the downstream neighbours-without being able to enforce the reward. Uzbekistan and Kazakhstan, on the other hand, are less inclined to send fossil fuels to Kyrgyzstan if they fear that the latter will deviate from the agreement by releasing large volumes of water in winter. The Syr Darya conflict therefore has the nature of a trust game, reminiscent of those that have been extensively studied in the experimental economics literature (e.g. Fehr et al. 1993; Berg et al. 1995; Dufwenberg and Gneezy 2000; Fershtman and Gneezy 2001; Gächter and Falk 2002; Cox et al. 2008). ${ }^{8}$ In trust (or reciprocity) games a first mover can send money to a second mover, who in turn can voluntarily reward the trustor by sending money back. The games are constructed such that by doing so, both players can be better off with respect to final payoffs, but in equilibrium no trust and no rewarding would be exhibited. Contrary to the theoretical prediction, the common finding of these studies is that first movers often show trust by passing money, and second movers often reward them by sending money back, even if the game is played only once and under completely anonymous conditions. In light of these findings the poor record of cooperation in the Central Asian river conflict looks surprising. However, the games in the literature use artificial payoff structures which differ from those underlying the Syr Darya river game, and involve only two players.

The economic literature on transboundary river sharing includes inter alia contributions by Barrett (1994), Dinar and Wolf (1994), Moller (2004), Rogers (1997), Kilgour and Dinar (2001) and Ambec and Sprumont (2002). These, mainly theoretical, contributions are preoccupied with how and under what circumstances riparians can attain cooperative outcomes in conflicts over water quantity sharing, but they do not address inter-temporal conflicts arising over upstream hydropower and downstream irrigation use. Most of the economic literature that does address this type of conflict typically deals with inter-state rivers, especially in the United States, rather than rivers crossing international borders. Particularly pertinent are the studies of the Snake-Columbia river by McCarl and Ross (1985), Houston and Whittlesey (1986), McCarl and Parandvash (1988), and Hamilton et al. (1989). The Colorado river has been analysed by Gisser et al. (1979) and the irrigation districts in Central California by Chatterjee et al. (1998). The study by Owen-Thomsen et al. (1982) of Egypt's High Aswan Dam represents an exception to the focus on US-based rivers. These studies use mathematical programming to analyse the impacts on the agricultural sector of a water transfer to hydropower production because the latter often has the highest marginal productivity. Authors such as Hamilton et al. (1989) consider the possible role of market mechanisms to improve the resource allocation. Others, such as Chatterjee et al. (1998), have emphasised the establishment of clearer property rights. Both of these policy remedies, however, are less suitable in an international context. International trade in water is rare, partly because the conflicting principles of international law complicate the property rights issue.

There are just three economic studies of an international hydropower-irrigation conflict. Aytemiz (2001) examines the conflict between Turkey and Syria on the Euphrates. Moller (2005a, b) develops a theoretical model of the Syr Darya conflict. He takes a noncooperative approach by examining the conflict-reducing impact of a range of infrastructure projects. Construction of downstream reservoirs is found to reduce conflict through a Pareto-improvement, but it does not lead attainment of basinwide efficiency (Pareto-optimality). World Bank (2004a) takes a cooperative approach to the Syr Darya conflict by examining how side pay-

8 Irlenbusch (2005a, b) reports results from a slightly more complex game, but with the non-binding contracts that characterise the real game. 
ments can be used to attain efficient outcomes. It demonstrates that net Syr Darya basin benefits are substantially higher when the Toktogul reservoir is operated in an 'irrigation mode' than under the 'power mode'. Developed before the collapse of the barter agreements, the report recommends a number of ways in which the existing regional cooperation mechanisms could be improved. These include inter alia proposals to use multi-year rather than annual agreements, a 'letter of credit scheme' and the introduction of a monitoring and guarantee mechanism to ensure compliance with agreed obligations. Riparian governments are yet to implement any of these proposals (see World Bank 2004b for details).

Building on the work contained in World Bank (2004a) our paper also explores the scope for cooperation in the Syr Darya conflict. Using similar assumptions about key economic variables we develop a more general economic model which is then used for laboratory experiments. ${ }^{9}$ There are three major differences between our model and that in World Bank (2004a). The first relates to different assumptions about water availability. We assume an average annual water outflow of around $13 \mathrm{BCM}$ compared to $9 \mathrm{BCM}$ used in the World Bank report. The latter figure has been discredited (as World Bank 2004b concedes) because it is based on a non-homogenous data set for the 1911-2000 period compiled by BVO Syr Darya (a basinwide agency located in Tashkent) which under-records inflow since 1975. Secondly, the Bank report compares two different water allocations (irrigation and power mode) while we generalise the analysis by considering a continuum of allocations within the historically relevant range. Thirdly, and as a consequence, we have introduced several capacity constraints to provide a realistic treatment of extreme scenarios. The subsequent section develops the model and details the design of the experiment.

\section{The Model and Experimental Design}

Before formulating the economic model we had to make some choices. First, since Uzbek reservoirs are at an advanced stage of construction we decided mainly to focus on these in the experiment, and not to include the Kazakh reservoirs because the government has not yet approved their construction. Further, we neglect the impact of winter flooding, though this is a much-discussed concern of the Uzbek and Kazakh governments. Reliable estimates of the damages of flooding proved impossible to obtain, but there are some indications that the economic costs of flooding are relatively small. The most substantial damage seems to be political, since flooding is a very visible event likely to stir public anger.

\subsection{The Stage Game}

We first turn our attention to the strategic environment. The Syr Darya river conflict is characterised by negotiations between governments of the three countries and the problem of their subsequent implementation. Consequently, we design a game that consists of two stages. First, in a negotiation stage the three players-each representing a country-are given the opportunity to make a contract on a combination of water releases and possible side payments. This contract, however, is non-binding, as there is no way in which a country can be forced to obey (leaving aside the unlikely possibility of military intervention). In the second

\footnotetext{
9 Experiments on games informed by real-world data are surprisingly rare. Some have been carried out in the course of consulting projects for spectrum auctions, but their results are often not published due to confidentiality concerns of the clients (an exception is Abbink et al. 2002). In a different context, Güth et al. (2008) parameterise a bargaining game with data from a case study on the film industry. Abbink et al. (2008) use data from Zambian maize markets to inform an oligopoly experiment.
} 
stage of the game the players decide on the water releases and side payments they actually implement.

In the real conflict negotiations take place annually in trilateral negotiations. In the experimental design we attempt to model such a scenario. However, to make it playable in the laboratory we need to impose a certain structure on the negotiations, which takes into account that laboratory time is limited. At the first stage of the game, therefore, one player makes a proposal to the other two players. We chose to draw the proposer at random in each round of the game (each with a probability of one third), in the absence of a natural candidate. After the proposal is specified, its terms are communicated to the other two players. These players are then simultaneously asked to accept or reject it. Since the contract is non-binding, the negotiation part of the game is merely 'cheap talk' in the game theoretic sense. It may be used to co-ordinate the players' behaviour, but it cannot be enforced and does not restrict the players in their subsequent actions. A proposal consists of four elements: (1) The amount of water that Kyrgyzstan releases to Uzbekistan from Toktogul in summer. (2) The amount of water that Uzbekistan passes on to Kazakhstan. (3) A compensation payment that Uzbekistan makes to Kyrgyzstan, and; (4) a compensation payment that Kazakhstan makes to Uzbekistan.

After the proposal has been either accepted or rejected, the players make the decisions for real in stage two of the game. As the first mover Kyrgyzstan decides on a release of water from Toktogul. At the next stage Uzbekistan makes two decisions at once. It chooses which quantity of water to release to Kazakhstan, and an amount of money to pay to Kyrgyzstan. As the final step of the stage game, Kazakhstan decides on a side payment to make to Uzbekistan. At all stages are the players informed about all players' decisions at preceding stages.

The natural inflow into the Kyrgyz reservoir, Toktogul, is exogenously given and known. Uzbekistan can release to Kazakhstan any quantity of water up to what it receives from Kyrgyzstan. The compensation payments are amounts of money. This represents a simplification of conduct of play in the real conflict, where Uzbekistan refuses to make any monetary payments in exchange for water or to attach a price on water (services) - a demand from the Kyrgyz side. In practice, however, Uzbekistan has implicitly agreed to pay compensations through an inflated price for the electricity it receives from Kyrgyzstan in summer. Simplicity is important for the experiment and we therefore decided not to model these additional behavioural complexities.

\subsection{Costs, Benefits, and Payoff Functions}

For the payoffs associated with the discharge of water we estimate a model from the available data, following World Bank (2004a). The payoff functions of the three riparians and their estimations are described in detail in Appendix A. Kyrgyz payoff depends positively on the net energy balance and side payments received from Uzbekistan. The exogenous energy demand of Kyrgyzstan can be met through hydropower or thermal power production. Uzbekistan's payoff is a positive function of cotton production, hydropower imports from Kyrgyzstan and the net side payments received (what it receives from Kazakhstan less what it pays to Kyrgyzstan). Kazakh payoffs are similar to those of Uzbekistan, depending positively on cotton production, energy imports, but negatively in its own side payment to Uzbekistan.

The marginal productivity of water turns out to be highest in downstream cotton production within the relevant ranges, given the estimated parameters of the model. Basinwide efficiency (or total payoff) can therefore be enhanced through higher Kyrgyz summer discharges relative to its noncooperative choice. The model can usefully be expressed as the 


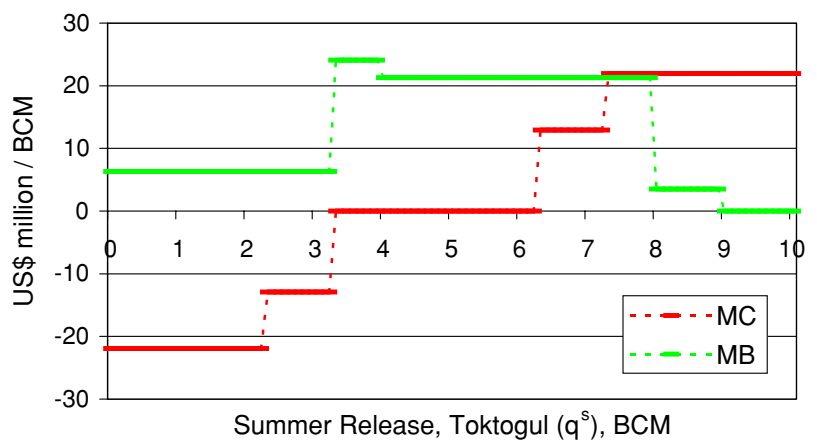

Fig. 2 Marginal costs (MC) and marginal benefits (MB), $Q=13$

cost incurred by Kyrgyzstan from discharging additional water and the associated benefits arising to downstream countries. Costs and benefits are a function of the total water inflow to the Toktogul reservoir, $\mathrm{Q}$, and Kyrgyzstan's discharge of water in the summer, $\mathrm{q}_{\mathrm{ky}}^{\mathrm{S}} \cdot{ }^{10}$ To illustrate the properties of the model we use a normal water year $(\mathrm{Q}=13 \mathrm{BCM})$ as a benchmark and show marginal costs and benefits as a function of Kyrgyz summer discharge (see Fig. 2). ${ }^{11}$

Marginal costs and benefits are constant, piecewise linear and each schedule has five steps. Consider first each of these steps on the marginal benefit curve starting from left: (1) For low Kyrgyz water discharges, downstream marginal benefits are limited to cotton irrigation only. (2) Marginal benefits increase for higher discharges as this generates a Kyrgyz energy surplus in the summer period and results in cost savings for energy importing downstream countries. (3) Marginal benefits then fall slightly as Kazakh irrigation demands are saturated. (4) They fall further as a capacity constraint of electricity exports becomes binding. (5) Marginal benefits eventually reach zero as Uzbekistan receives sufficient irrigation water.

Marginal costs (of Kyrgyzstan) are determined by summer as well as winter effects. Low summer releases are associated with a domestic Kyrgyz energy deficit in summer (and a surplus in winter) while the reverse is the case for high discharges. The five steps on the marginal cost curve are characterised as follows: (1) For low water discharge values in the summer period, Kyrgyzstan have to operate both of its thermal power plants (Bishkek I and II) as insufficient hydropower will be generated relative to energy demand. Each additional water unit released produces relatively more hydropower and reduces the marginal need for thermal power generation, and marginal costs are therefore negative (i.e. Kyrgyzstan incurs a marginal benefit). (2) As summer discharges increase, the marginal cost savings of hydropower production fall as it substitutes only for the relatively cheaper Bishkek I plant (Bishkek II is no longer needed to satisfy the Kyrgyz energy demand). As a result marginal costs increase, but remain negative. (3) Marginal costs equal zero when the primary energy balance of Kyrgyzstan is non-negative in both seasons and the country relies exclusively on hydropower. (4) For higher discharges marginal costs (of operating Bishkek I) become

\footnotetext{
10 Winter discharge from Kyrgyzstan is determined residually as $\mathrm{Q}-\mathrm{q}_{\mathrm{ky}}^{\mathrm{S}}$. See Appendix A for a discussion of this assumption.

11 In this subsection, we further assume, for illustrative purposes, that water is shared equally between the two downstream riparians. This assumption does not affect the properties of the model in any significant way. It merely affects the size of total benefits and the distribution of those benefits between Uzbekistan and Kazakhstan. Equal water sharing produces conservative benefit estimates because the potential for downstream optimisation is not necessarily exploited.
} 
Table 1 Model results for alternative values of the two treatment variables

\begin{tabular}{|c|c|c|c|c|c|c|c|}
\hline Q & 10 & 11 & 12 & 13 & 14 & 15 & 16 \\
\hline Noncooperative equilibrium $\left(\mathrm{q}_{\mathrm{ky}}^{\mathrm{s}}\right)$ & 3.3 & $3.3-4.2$ & $3.3-5.2$ & $3.3-6.2$ & $3.3-7.2$ & $3.3-8.2$ & $3.3-9.2$ \\
\hline Cooperative optimum $\left(\mathrm{q}_{\mathrm{ky}}^{\mathrm{S}}\right)$ & 4.2 & 5.2 & 6.2 & 7.2 & 7.9 & 8.3 & $9.0^{\mathrm{a}}$ \\
\hline \multicolumn{8}{|c|}{ Basinwide gains from Uzbek reservoirs (million US\$) } \\
\hline Noncooperative ${ }^{\mathrm{b}}$ & 8.8 & 8.7 & 8.8 & 8.8 & 6.3 & 2.8 & 0.0 \\
\hline Cooperative & 8.8 & 8.7 & 8.7 & 6.3 & 3.9 & 2.4 & 0.0 \\
\hline \multicolumn{8}{|c|}{ Basinwide gains of cooperation (million US\$) ${ }^{b}$} \\
\hline Without reservoirs & 9.5 & 9.0 & 9.0 & 9.0 & 6.4 & 0.0 & 0.0 \\
\hline With reservoirs & 9.5 & 9.0 & 8.9 & 6.5 & 4.0 & 0.0 & 0.0 \\
\hline
\end{tabular}

${ }^{\mathrm{a}} \mathrm{q}_{\mathrm{ky}}^{\mathrm{s}}=9.0$ without reservoirs but is given by the interval [7.9;9.2] with reservoirs

$\mathrm{b}$ Refers to the highest noncooperative water release

positive since a high summer release causes an energy deficit in winter as there is insufficient water to produce hydropower. (5) Marginal costs peak when the more expensive Bishkek II also needs to be operated in winter. Finally, we note that net benefits of cooperation are maximised at the intersection between the marginal cost and marginal benefit schedules, corresponding to running Toktogul in 'irrigation mode'

Table 1 illustrates the model results more generally allowing for variation in water inflow (Q) to Toktogul and the possibility of Uzbek reservoirs. Outcomes are highly sensitive to overall water availability within the historically relevant interval of 10 and $16 \mathrm{BCM}$ per year. The noncooperative equilibrium, determined by the Kyrgyz pay-off maximization choice, is non-unique. A summer discharge of 3.3 BCM is sufficient to eliminate the domestic energy deficit in summer. The end interval of the equilibrium is increasing in $\mathrm{Q}$ and is determined by the point where Kyrgyzstan incurs a domestic energy deficit in winter. The cooperative optimum, which maximizes the basinwide payoff is typically unique and increasing in $\mathrm{Q}$ because higher overall water availability reduces the Kyrgyz marginal costs in winter and shifts the right-hand part of the marginal cost schedule downwards. Cooperation typically involves a higher Kyrgyz summer discharge than noncooperation, except in high-water years where the two may be identical. Table 1 also illustrates the intuitive property that basinwide gains from cooperation are highest when water is scarce. ${ }^{12}$

The economic impact of the new Uzbek reservoirs are summarized as follows. Uzbek cotton benefits, and thus total basinwide benefits increase by up to US $\$ 8.8$ million depending on Q. By and large, the basinwide gain from Uzbek reservoirs is decreasing in Q, i.e. reservoirs are most useful in low-water years. Uzbek reservoirs may also make cooperation slightly less attractive as basinwide gains of cooperation fall slightly. Maximisation of basinwide efficiency requires regional cooperation (with or without reservoirs), except when water is abundant. In this sense reservoirs do not establish Uzbek self-sufficiency in irrigation water, i.e. Uzbekistan can increase its benefits even further by cooperating with the other riparians. For a normal water year we compute a cooperative surplus equal to US $\$ 9.0$ million per year.

\footnotetext{
12 Note that the value of basinwide gains depend on the selection of the non-unique, noncooperative equilibrium. Table 1 produces conservative estimates because we assume that the equilibrium with the highest release is selected. This is also the least inefficient one. Equilibria with lower releases do not benefit Kyrgyzstan but harm the downstream countries.
} 


\subsection{The Conduct of the Experiment}

Since the payoff functions developed from the available real-world data are complex, they needed to be presented in the simplest possible way for the experiment. We used tables that list the payoffs obtained by each combination of water releases from Kyrgyzstan to Uzbekistan and from Uzbekistan to Kazakhstan. Depending on the range of feasible releases these payoff tables could quickly become very large and incomprehensible. Therefore, the number of choices was restricted. Water discharges were limited to integer numbers. We further cut the strategy space in a way that Kyrgyzstan could only pass any integer number from 3 to 9. Releases outside this range are historically irrelevant and were not plausible choices. The resulting payoff tables consisted of 49 lines and four columns. The first three columns showed the payoffs for each of the three players, the last column the sum of the three payoffs (enabling participants to identify efficient outcomes). The payoff tables can be found in Appendix B.

For the specification of the payoff values from the payoff functions we had to make some choices. First, we adopted the principle that 'a dollar is a dollar', thus we did not account for a different marginal utility of money in the three countries. Those could arise from their different population sizes or GDP levels. Such corrections, however, would have been somewhat arbitrary (for example, in Kazakhstan water benefits apply to the South Kazakhstan and Qyzlorda provinces only). Further, such considerations do not seem to play a significant role in the actual policy debate. Secondly, in the theoretical model payoffs are formulated in additional costs of water release for Kyrgyzstan and additional benefits for the downstream riparians. In the experiments absolute payoffs needed to be implemented, thus the unspecified intercepts of the payoff functions had to be defined. We decided to choose the intercepts in a way which was most suitable experimentally, rather than derive them from some real-world benchmark (such as GDP). This way we could make sure that equal payoffs for the three players - a natural focal point in experiments - could be implemented in cooperative scenarios (thus cooperation was not impeded by incompatibility with possible equality considerations). Further, we had to make sure that different strategy choices could lead to substantially different payoffs in order to properly incentivise the participants. As a benchmark we chose the least inefficient noncooperative equilibrium outcome without reservoirs in the normal water year $(\mathrm{Q}=13)$, where Kyrgyzstan discharges 6 units $(\mathrm{BCM})$ and Uzbekistan releases 1 unit, since this is currently the most relevant scenario in reality. Payoffs were adjusted in a way that each player gets 370 talers (the experimental currency unit) in this scenario. From there we calculated all other payoffs using the cost and benefit functions derived earlier. Each taler difference between two numbers in the payoff tables corresponds to US $\$ 100,000$ per year in the real game. Note that side payments would be added or subtracted from these figures, such that a wide range of payoff combinations was achievable.

The experiment was conducted at the Centre for Decision Research and Experimental Economics (CeDEx) of the University of Nottingham. The software for the experiment was developed using the RatImage programming package (Abbink and Sadrieh 1995). Subjects were recruited by e-mail from a database of students, who had previously registered at CeDEx as potential participants in experiments. Each subject participated in only one session, and no subject had participated in experiments similar to the present one. The subjects were undergraduate students from a wide range of disciplines. The majority of participants were British. Among the substantial fraction of foreign students the largest group was Chinese. Virtually all subjects were aged between 19 and 25 , with a balanced gender distribution. ${ }^{13}$

13 Ideally we would have wished to conduct the experiment with participants from a Central Asian cultural background. However, few students from that region are enrolled at the University of Nottingham, and in 
In each session subjects interacted in fixed groups of three subjects. The role of a participant as representing Kyrgyzstan, Uzbekistan or Kazakhstan did not change throughout the experiment. This set-up reflects the repeated-game character of the real situation. Subjects were not told which of the other participants were in the same group, but they knew that the composition of the groups did not change. Each session began with an introductory talk. The experimenter read aloud the written instructions (see Appendix C). The language used in the instructions was semi-natural. The situation was framed as that of a 'resource being passed' from one player to the other, but we did not label the players as the three countries they represented. Since we did not expect many students to be familiar with the Syr Darya river conflict, we were concerned that an entirely natural framing would cause confusion. On the other hand we did not expect a benefit from completely disguising the situation using abstract terms as this would have made the instructions more difficult to understand.

We conducted 24 rounds of the stage game. ${ }^{14}$ These were divided into three phases of eight rounds, using the different inflow levels, Q, of 10, 13, and 16 to represent low, normal and high water levels, respectively. The order of the three phases was varied in a way that each water level was played in each of the phases in the same number of sessions. The different levels of inflow implied different payoff distributions, but otherwise the structure of the game remained the same in each phase.

Subjects were granted a capital balance of 1,000 talers at the outset of each session. The total earnings of a subject from participating in the experiment were equal to the capital balance plus the sum of all the payoffs he or she made during the experiment minus the sum of that subject's losses. A session lasted for about two hours (including time spent to read the instructions). At the end of the experiment, subjects were paid their total earnings anonymously in cash, at a conversion rate of one pound sterling for 400 talers. Subjects earned between $£ 3.44$ and $£ 39.10$ with an average of $£ 21.95$, which is considerably more than students' regular wage in Nottingham. At the time of the experiment, the exchange rate to other major currencies was approximately US $\$ 1.90$ and $€ 1.45$ for $£ 1$.

We conducted three sessions with four treatments. In the treatments we varied two dimensions. First, we ran sessions modelling the scenarios with and without Uzbek reservoirs. The treatments differed in the payoff tables, but not in the structure of the game. Second, we ran both scenarios with and without non-binding contracts or agreements. The latter treatment was motivated by the observation that contracts are frequently broken in the real conflict. Although contracts are cheap talk in a game theoretic sense, we wanted to examine whether their presence helped players to cooperate during the experiment.

Each session comprised of 12,15 , or 18 subjects, where the variation is due to showup rates. Subjects interacted with each other within groups but not across groups so that each group of three countries can be considered a statistically independent observation. With contracts, we gathered 15 independent observations in the treatment without reservoirs and

Footnote 13 continued

Central Asia we did not have access to a computerised laboratory. Experiments conducted with participants from different cultures sometimes show differences (Roth et al. 1991; Herrmann et al. 2008), sometimes not (Brandts et al. 2004; Cameron et al. 2005). Typically the differences are not large and would not lead to radically different conclusions.

14 Subjects were informed about the number of rounds for reasons of transparency and practicality. This creates a deviation from the real situation which resembles an infinitely repeated game. Contrary to the real-life decision makers, subjects could theoretically solve the 24-round supergame by backward induction and be guided by this solution. However, since such behaviour is virtually never observed in any experiment (and greatly at odds with the existing evidence from trust games), it seems unlikely to be the case in our setting. 
Table 2 Equilibria and Pareto optima of the game

\begin{tabular}{lll}
\hline Scenario & Subgame perfect equilibria & Pareto optima \\
\hline $\mathrm{Q}=10$, no reservoirs & $(3,0)$ & $(6,2)$ \\
$\mathrm{Q}=13$, no reservoirs & $(4,0),(5,0),(6,0),(6,1)$ & $(7,2)$ \\
$\mathrm{Q}=16$, no reservoirs & $(4,0),(5,0),(6,0),(6,1)$, & $(8,2),(8,3),(9,2), \ldots,(9,4)$ \\
& $(7,0), \ldots,(7,2),(8,0), \ldots,(8,3)$, & \\
$\mathrm{Q}=10$, with reservoirs & $(3,0), \ldots,(9,4)$ & $(4,2)$ \\
$\mathrm{Q}=13$, with reservoirs & $(4,0), \ldots,(4,2),(5,0), \ldots,(5,3),(6,0), \ldots,(6,4)$ & $(7,2), \ldots,(7,5)$ \\
$\mathrm{Q}=16$, with reservoirs & $(4,0), \ldots,(4,2),(5,0), \ldots,(5,3)$, & $(8,2), \ldots,(8,6),(9,2), \ldots,(9,7)$ \\
& $(6,0), \ldots,(6,4),(7,0), \ldots,(7,5)$, & \\
& $(8,0), \ldots,(8,6),(9,0), \ldots,(9,7)$ & \\
\hline
\end{tabular}

16 in the treatment with Uzbek reservoirs. Without contracts the number of independent observation is 16 without and 17 with reservoirs.

\subsection{Game-Theoretic Considerations}

Using the payoff tables shown in Appendix B, the subgame perfect equilibria (Selten 1965, 1975) of the stage game can easily be identified with a backward induction argument. It is straightforward to see that in a noncooperative equilibrium no side payments are made. At the last stage a side payment only reduces Kazakhstan's payoff. Since the other players' decisions are taken, Kazakhstan cannot gain anything from making a final payment. Analogously, Uzbekistan does not gain from making a side payment to Kyrgyzstan, since Kyrgyzstan's decision is already made.

The equilibrium choices with respect to water releases can be obtained from the payoff tables. Since Kyrgyzstan foresees that it will not receive compensation payments, its payoff is not affected by the choices being made downstream. Thus it will simply release the quantity that maximises its own payoff. ${ }^{15}$ For example, in the benchmark case of $\mathrm{Q}=13$ without reservoirs, Kyrgyzstan can release anything from 4 to 6 units in an equilibrium and earn 370 talers (see Table 11 in Appendix B). Uzbekistan then chooses the quantity to pass to Kazakhstan given this behaviour. If Kyrgyzstan has chosen, for example, 6 units, then Uzbekistan passes on 0 or 1 units to Kazakhstan. ${ }^{16}$ Thus, the combinations $\left(\mathrm{q}_{\mathrm{ky}}^{\mathrm{s}}, \mathrm{q}_{\mathrm{uz}}\right)=(4,0),(5,0),(6,0)$ and $(6,1)$, combined with no side payments, constitute subgame perfect equilibria of the game. Table 2 illustrates the subgame perfect equilibria and Pareto optima for all six scenarios.

The table shows that for the case of abundant water $(\mathrm{Q}=16)$, there is no conflict between own-payoff maximisation and cooperation, since the Pareto-optimal outcomes are also equilibria of the game. In normal or low water years, sustaining the Pareto-optimum requires the players to deviate from the noncooperative equilibrium. The construction of the Uzbek reservoir widens the range of equilibria and in some cases the range of Pareto optima as well.

15 This feature eases the game-theoretic analysis, as we do not require a full-fledged backward induction analysis. However, a complete analysis is not difficult.

16 Note that passing on zero does not imply that the Syr Darya is dry at the Uzbek-Kazakh border. We examine only the Naryn cascade, but as mentioned earlier, the river is also fed from other sources notably the Kara Darya. Since other sources are generally unregulated, their inflow levels are not strategic variables in the game and thus excluded. 
Interestingly, even after building the reservoirs there is still room for improvement through cooperation. Still, in the case of low and normal water years the players can increase their payoffs by agreeing on a non-equilibrium solution.

\section{Results}

In this section we present the results of the experimental data. Our main focus is the efficiency implications of the new Uzbek reservoirs and the possibility of cooperation under the two regimes. For readability we will continue to label the players with the names of the countries they represent, though in fact they were experimental participants.

\subsection{Kyrgyz Discharges from Toktogul}

The economic efficiency of the outcome crucially relies on cooperation between Kyrgyzstan and Uzbekistan. We therefore first examine the behaviour of the participants representing the Kyrgyz side. Table 3 shows the relative frequency with which the different levels of Kyrgyz water release occur in the experimental data.

In low water years we observe that the noncooperative choice is dominant in the data. Recall that with $\mathrm{Q}=10$ (no reservoirs) the noncooperative release is 3 units and the Paretooptimal choice is 6 units. The choice generating the efficient solution is made in only $5 \%$ of the cases, while in more than half of the years we observe the noncooperative release. Thus the subjects representing Kyrgyzstan did not show much trust in their downstream counterparts. This may be surprising given the high incidence of trustful choices in previous experiments on reciprocity games. A possible explanation is the high risk that Kyrgyzstan must take when deviating from the noncooperative ( 3 units) to the Pareto optimal choice (6 units). Under

Table 3 Relative frequency of Kyrgyz choices regarding Toktogul release

\begin{tabular}{|c|c|c|c|c|c|c|c|}
\hline \multicolumn{8}{|c|}{ With contracts } \\
\hline & \multicolumn{7}{|c|}{ Quantity passed by Kyrgyzstan } \\
\hline Treatment & 3 & 4 & 5 & 6 & 7 & 8 & 9 \\
\hline $\mathrm{Q}=10$, no reservoirs & $\underline{0.562}$ & 0.298 & 0.083 & 0.050 & 0.008 & 0.000 & 0.000 \\
\hline $\mathrm{Q}=13$, no reservoirs & $\overline{0.050}$ & $\underline{0.142}$ & $\underline{0.083}$ & $\underline{0.383}$ & 0.333 & 0.008 & 0.000 \\
\hline $\mathrm{Q}=16$, no reservoirs & 0.017 & $\underline{0.075}$ & $\overline{0.050}$ & $\overline{0.117}$ & $\underline{0.008}$ & $\underline{0.258}$ & $\underline{0.475}$ \\
\hline $\mathrm{Q}=10$, with reservoirs & $\underline{0.586}$ & $\overline{0.188}$ & $\overline{0.164}$ & $\overline{0.023}$ & $\overline{0.023}$ & $\overline{0.016}$ & $\overline{0.000}$ \\
\hline $\mathrm{Q}=13$, with reservoirs & 0.023 & $\underline{0.102}$ & $\underline{0.039}$ & $\underline{0.500}$ & 0.234 & 0.094 & 0.008 \\
\hline $\mathrm{Q}=16$, with reservoirs & 0.047 & $\underline{0.102}$ & $\underline{0.031}$ & $\underline{0.078}$ & $\underline{0.055}$ & $\underline{0.305}$ & $\underline{0.383}$ \\
\hline \multicolumn{8}{|c|}{ Without contracts } \\
\hline & \multicolumn{7}{|c|}{ Quantity passed by Kyrgyzstan } \\
\hline Treatment & 3 & 4 & 5 & 6 & 7 & 8 & 9 \\
\hline $\mathrm{Q}=10$, no reservoirs & 0.633 & 0.283 & 0.067 & 0.008 & 0.000 & 0.000 & 0.008 \\
\hline $\mathrm{Q}=13$, no reservoirs & $\overline{0.039}$ & $\underline{0.164}$ & $\underline{0.125}$ & $\underline{0.516}$ & 0.156 & 0.000 & 0.000 \\
\hline $\mathrm{Q}=16$, no reservoirs & 0.031 & $\overline{0.156}$ & $\overline{0.055}$ & $\overline{0.156}$ & $\underline{0.086}$ & $\underline{0.148}$ & $\underline{0.367}$ \\
\hline $\mathrm{Q}=10$, with reservoirs & $\underline{0.603}$ & $\overline{0.301}$ & $\overline{0.088}$ & $\overline{0.007}$ & $\overline{0.000}$ & $\overline{0.000}$ & $\overline{0.000}$ \\
\hline $\mathrm{Q}=13$, with reservoirs & 0.000 & 0.162 & $\underline{0.184}$ & 0.522 & 0.110 & 0.022 & 0.000 \\
\hline $\mathrm{Q}=16$, with reservoirs & 0.022 & $\underline{0.125}$ & $\overline{0.074}$ & $\overline{0.110}$ & $\underline{0.074}$ & $\underline{0.191}$ & $\underline{0.404}$ \\
\hline
\end{tabular}

Note: Modal frequencies are set in bold face; Subgame perfect equilibria are underlined; Pareto optima in grey 
this scenario Kyrgyzstan renounces 477 talers (US\$ 47.7m), and to gain maximum benefits relies on receiving at least as much as a side payment from Uzbekistan. To make such a high payment Uzbekistan would need to trust Kazakhstan to cooperate as well. Given that the total benefit from cooperation (the pie that can be divided among the two players on top of the noncooperative payoffs) is only 189 talers (US\$ $18.9 \mathrm{~m}$ ), it is quite plausible that the players representing Kyrgyzstan in the laboratory deemed cooperation too risky.

Though the new reservoirs reduce Kyrgyzstan's risk of cooperation considerably for $\mathrm{Q}=10$ (the Pareto optimal release is then only 4 units and requires Kyrgyzstan to renounce only 61 talers), the effect on the likelihood of cooperation is minor. While the frequency of Pareto optimal releases increases significantly from 5.0 to $18.8 \%$ ( $\alpha=0.025$ one-sided, Fisher's two-sample randomisation test) it is still low, and there is an absolute majority of noncooperative choices. The effect is similar in the case without contracts, in which the frequency of Pareto optimal choices increases from 0.8 to $30.1 \%$. Thus even with the reduced risk for Kyrgyzstan the structure of the game imposes substantial hurdles to cooperation between the riparians.

In normal water years $(\mathrm{Q}=13)$ the noncooperative choice is also most frequent, and we even observe a substantial fraction of spiteful decisions (releases of 4 or 5 units, which yields the maximum payoff for Kyrgyzstan but harm Uzbekistan). These may be acts of punishment against the Uzbek player in response to default on side payments. Taking together the three equilibrium options (4, 5 and 6 units) we observe noncooperative behaviour in more than $60 \%$ of the cases (even more than $80 \%$ in the treatment without contracts). However, the prospect for cooperation is not as bleak as in low-water years. Without reservoirs the Pareto optimal release ( 7 units) is chosen frequently, especially in the treatment with contracts, where it is realised in one third of the rounds (without contracts the frequency is substantially, but not statistically significantly, lower). These results are independent of the new reservoirs, which do not have a statistically significant effect on cooperation.

When water is abundant $(\mathrm{Q}=16)$ participants usually do not find it difficult to implement and sustain one of the efficient outcomes (a release of 8 or 9 units). However, note that in high water years there is no conflict between individual payoff maximisation and efficiency, such that this result does not hint at strong efforts to cooperate. In high-water years the new reservoirs are practically obsolete, and consequently they do not have a significant effect on the experimental results. ${ }^{17}$

\subsection{Uzbek Compensation to Kyrgyzstan}

In order for all three countries to benefit from cooperation Uzbekistan needs to compensate Kyrgyzstan for its summer release of water. Table 4 shows Uzbekistan's median side payment to Kyrgyzstan, conditional on the quantity of water that Kyrgyzstan has released in summer. It emerges that Uzbekistan's reluctance to make sufficient payments is a source of cooperation failure. This is particularly pronounced in low water years without reservoirs. Recall that Kyrgyzstan renounces 477 talers $(\$ 47.7 \mathrm{~m})$ when moving from the noncooperative equilibrium to the Pareto optimum. The experimental Kyrgyzstan players who did so received a mere 25 talers $(\$ 2.5 \mathrm{~m})$ back, in the median, as compensation in the treatment with contracts. ${ }^{18}$ In the presence of Uzbek reservoirs Kyrgyzstan typically did not receive any reward

17 Note that the Uzbek reservoirs are too small to enable multi-year regulation, i.e. to benefit from storing water inflows in high-water years and using it in low-water years.

18 In the treatment without contracts there was an insufficient number of observations to derive a meaningful statistic. The pareto optimal Kyrgyz release was chosen only once. 


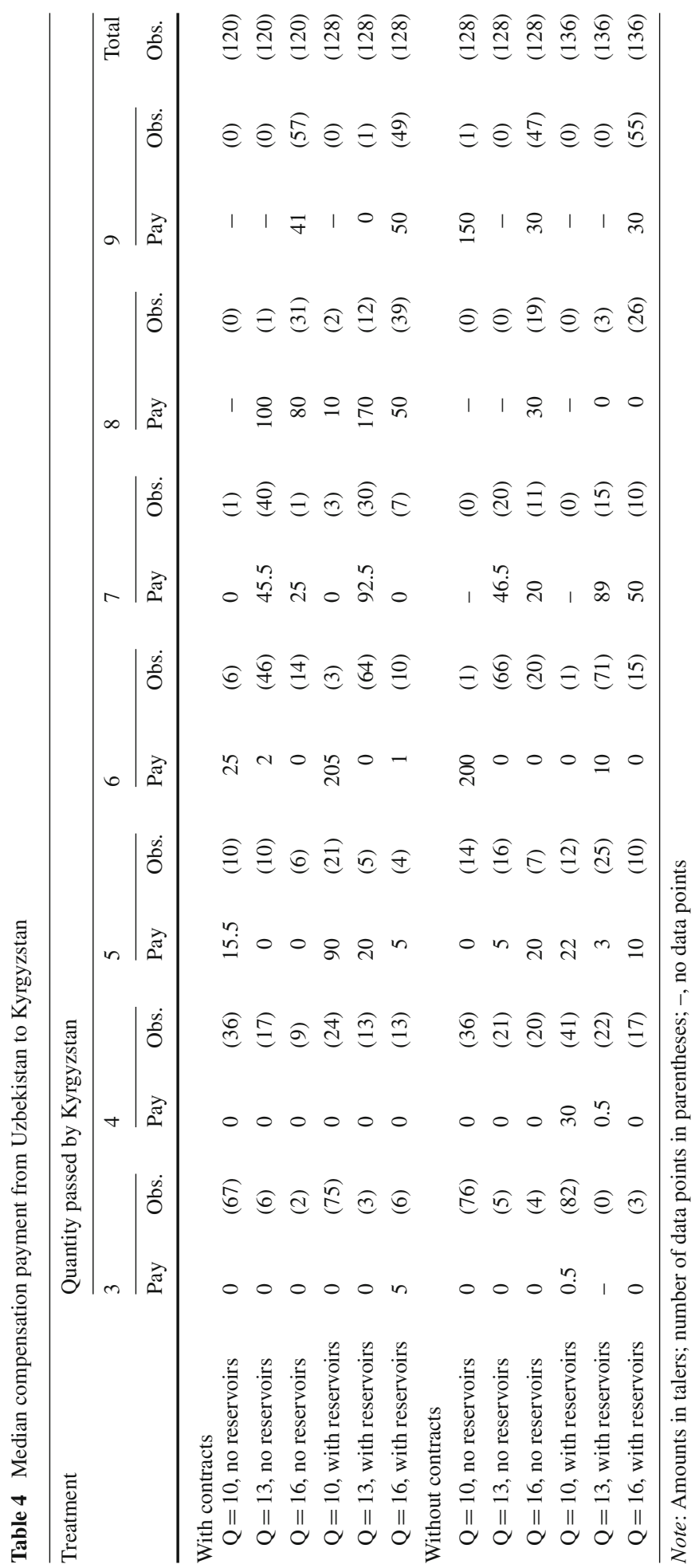


for releasing the efficient 4 units. This explains the low level of cooperation we observe in low water years despite the fact that reservoirs make cooperation less risky. For $Q=13$ Kyrgyzstan must forego 98 talers to sustain a Pareto optimal outcome (with and without reservoirs), but the median Uzbek compensation payment generally falls short of this. Only in the treatment with reservoirs and without contracts does the median compensation exceed Kyrgyzstan's foregone payoffs. In the other treatments the figure is between 45.5 and 92.5 talers. Interestingly the presence of contracts seems to worsen Uzbekistan's willingness to compensate Kyrgyzstan, but the data are too sparse to obtain statistical significance. Finally, in high-water years we also observe some use of side payments. Although Kyrgyzstan receives the same payoff in the interval 4-9 units, its decision greatly affects Uzbekistan. Therefore, Uzbekistan may choose to use side payments to reward Kyrgyzstan for non-spitefulness thereby sustaining high releases.

\subsection{Downstream Collaboration}

The downstream riparians, Uzbekistan and Kazakhstan, rely on Kyrgyzstan's behaviour in order to achieve maximum payoffs. However, even without Kyrgyzstan's good will they often have room for improving their payoffs by cooperating. For each subgame (defined by Kyrgyzstan's release) we can identify a noncooperative equilibrium. In the payoff table this is obtained where Uzbekistan's payoff within one cell of equal releases from Kyrgyzstan is highest. For example, suppose that in a normal water year without reservoirs Kyrgyzstan has chosen to release 6 units. Uzbekistan's payoff is then maximised if it passes either 0 or 1 units. Thus both choices constitute a noncooperative equilibrium for the subgame with a Kyrgyz release of 6 units. The Pareto optimum can also be identified for each subgame separately, and is characterised as the Uzbek choice that maximises the total payoff within the cell. In the above example, Uzbekistan should pass 2 units.

Table 5 Frequency of Uzbekistan's passed quantities

\begin{tabular}{|c|c|c|c|c|c|}
\hline Treatment & $\begin{array}{l}\text { (A) } \\
\text { Pareto optimum, } \\
\text { but not } \\
\text { equilibrium }\end{array}$ & $\begin{array}{l}\text { (B) } \\
\text { Equilibrium, but } \\
\text { not Pareto } \\
\text { optimum }\end{array}$ & $\begin{array}{l}\text { (C) } \\
\text { Pareto optimum } \\
\text { and equilibrium }\end{array}$ & $\begin{array}{l}\text { (D) } \\
\text { Other }\end{array}$ & Total \\
\hline \multicolumn{6}{|l|}{ With contracts } \\
\hline $\mathrm{Q}=10$, no reservoirs & 0.050 & 0.075 & 0.717 & 0.158 & 1.000 \\
\hline $\mathrm{Q}=13$, no reservoirs & 0.075 & 0.325 & 0.417 & 0.183 & 1.000 \\
\hline $\mathrm{Q}=16$, no reservoirs & 0.034 & 0.184 & 0.683 & 0.100 & 1.001 \\
\hline $\mathrm{Q}=10$, with reservoirs & 0.000 & 0.547 & 0.430 & 0.023 & 1.000 \\
\hline $\mathrm{Q}=13$, with reservoirs & 0.000 & 0.500 & 0.492 & 0.008 & 1.000 \\
\hline $\mathrm{Q}=16$, with reservoirs & 0.000 & 0.336 & 0.664 & 0.000 & 1.000 \\
\hline \multicolumn{6}{|l|}{ Without contracts } \\
\hline $\mathrm{Q}=10$, no reservoirs & 0.016 & 0.094 & 0.789 & 0.102 & 1.001 \\
\hline $\mathrm{Q}=13$, no reservoirs & 0.078 & 0.547 & 0.305 & 0.070 & 1.000 \\
\hline $\mathrm{Q}=16$, no reservoirs & 0.063 & 0.289 & 0.578 & 0.070 & 1.000 \\
\hline $\mathrm{Q}=10$, with reservoirs & 0.000 & 0.471 & 0.500 & 0.029 & 1.000 \\
\hline $\mathrm{Q}=13$, with reservoirs & 0.000 & 0.500 & 0.471 & 0.029 & 1.000 \\
\hline $\mathrm{Q}=16$, with reservoirs & 0.000 & 0.404 & 0.596 & 0.000 & 1.000 \\
\hline
\end{tabular}


Table 6 Frequency of agreements

\begin{tabular}{lll}
\hline Treatment & $\begin{array}{l}\text { Years with } \\
\text { agreement }\end{array}$ & $\begin{array}{l}\text { Fraction of } \\
\text { broken agreements }\end{array}$ \\
\hline $\mathrm{Q}=10$, no reservoirs & 0.308 & 0.865 \\
$\mathrm{Q}=13$, no reservoirs & 0.525 & 0.746 \\
$\mathrm{Q}=16$, no reservoirs & 0.625 & 0.587 \\
$\mathrm{Q}=10$, with reservoirs & 0.414 & 0.887 \\
$\mathrm{Q}=13$, with reservoirs & 0.508 & 0.785 \\
$\mathrm{Q}=16$, with reservoirs & 0.648 & 0.663 \\
\hline
\end{tabular}

As illustrated in Table 5, Uzbekistan's choice can fall into one of four categories depending on whether it is a Pareto optimum and/or a noncooperative equilibrium or neither. The table shows that efforts to cooperate between the downstream riparians have been modest. Pareto optima are mainly chosen when they happen to be noncooperative equilibria as well. When they are not equilibria they have only been implemented very few times. Noncooperative equilibrium play is therefore the dominant outcome. In the treatment with reservoirs, virtually all of Uzbekistan's decisions fall into that category. Since Pareto optima often coincide with equilibrium choices in the subgames, this behaviour is not always inefficient. In at least $43 \%$ of cases the most efficient downstream solution was realised.

\subsection{The Contracts and Their Adherence}

In all six variants of the game (with contracts) participants find it difficult to come to an agreement, and if they do these agreements are frequently broken (Table 6). When water is scarce $(\mathrm{Q}=10)$ an agreement is made in only about a third of the rounds, and from these more than three-quarters are broken. The record is best when water is abundant and there is no conflict between short-run self-interest and cooperation. Still, even in those years a majority of contracts are not adhered to. In this case, however, the high rate of broken contracts may just reflect that contracts are not considered necessary and are therefore taken less seriously. Recall that in high water years there are a range of Pareto optimal choices. If the one implemented is different from the one that has been agreed on this then does not necessarily have negative consequences for the players.

As a consequence of the frequent failure of non-binding contracts, the effects of the contracts themselves are very minor. As Tables 3, 4, 5 have indicated, the findings do not depend on whether players sign a contract first before deciding how to share the resource. Players are not more cooperative if they have the opportunity to make an agreement first. Though contracts in this game are not binding, they could have served as a coordination device or as an instrument to build up trust. However, it turns out that the contracts are not worth much in this respect. They do not improve cooperation significantly and do therefore not lead to more efficient outcomes, as the following analysis will show.

\subsection{Efficiency}

The total payoff gained by the three players jointly gives a measure of the efficiency of the experimental outcomes. Figure 3 illustrates the median total payoff for the different treatments as well as the efficiency loss, measured as the difference between the actual payoff and potential payoff in the Pareto optimum. Efficiency losses are sizeable, particularly in low and normal water years. Recall that the intercept terms of the payoff functions are unspeci- 


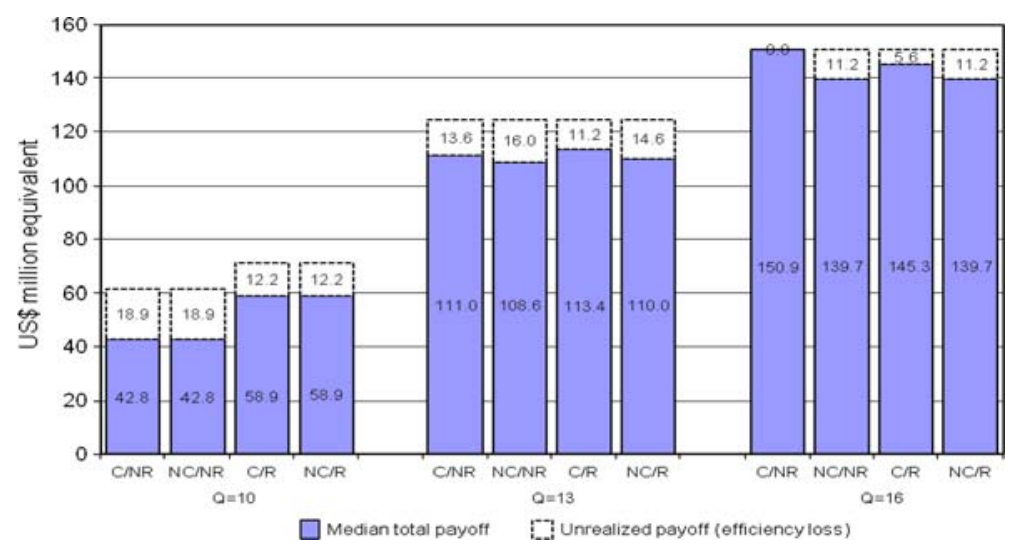

Fig. 3 Median total payoff (in US\$ equivalents). Note: $\mathrm{C}=$ contracts, $\mathrm{NC}=$ No contracts, $\mathrm{R}=$ With reservoirs, $\mathrm{NR}=$ Without reservoirs

fied. Thus, while payoffs of different treatments can be compared to each other, the absolute payoff values are partly determined by our choice for the experimental payoff tables.

As expected, high-water years lead to higher payoffs - a finding which is significant for all pairwise comparisons between two water levels in a given treatment $(\alpha<0.0001$, binomial test). The positive impact of reservoirs, however, is limited to low-water years. In those years reservoirs increase the median total payoff significantly $(\alpha<0.0001$, Fisher's two-sample randomisation test) and substantially by 161 talers (US\$16.1 million equivalent). ${ }^{19}$ Precisely the same figures are obtained for the treatment without contracts. ${ }^{20}$ The slight rise in payoff from introducing reservoirs during normal water years is not significant. When water is abundant we even observe a slight decrease in economic efficiency in the treatment with contracts (no effect at all without), although this difference is statistically insignificant.

\subsection{Dynamic and Individual Variation}

The poor efficiency achieved in our experiment cannot be attributed to inexperience of subjects in early rounds either. In the experiment, subjects played the river conflict game in 24 rounds, divided into three blocks of eight rounds, where the inflow level was varied across the blocks. Figure 4 shows the development of efficiency during the course of play, again measured as the total payoff of the three players. No systematic trend of efficiency variations over time is observed. The figure does reveal some individual sample variation, with the exception of low water years where efficiency is stable in all treatments and cohorts. Some groups of individuals exhibit a more erratic behaviour than others, although this is not systematic across the four treatments of our experiment. ${ }^{21}$

19 This figure is higher than the theoretical value in Table 1. The difference stems mainly from the restrictive assumption on water sharing that we drop in the experimental design. Further influences are the slightly higher incidence of cooperative outcomes with reservoirs and the restriction to integer releases.

20 This is explained by the fact that the figure shows median values, not averages. For example, in the case without reservoirs the bulk of observations involved Kyrgyzstan releasing 3 and Uzbekistan passing 0 units. This was the behaviour in the median observation in both treatments and results in the same total payoff.

21 Each subject played with all three inflow levels, where we varied the sequence in which the three levels followed one another. Within one treatment, the graphs in Fig. 4 with the circular markers (blue) depict values 

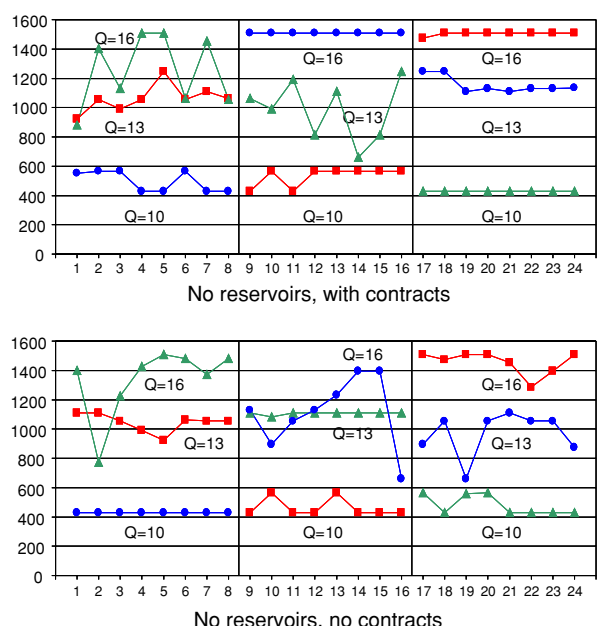

Fig. 4 Median total payoff over time
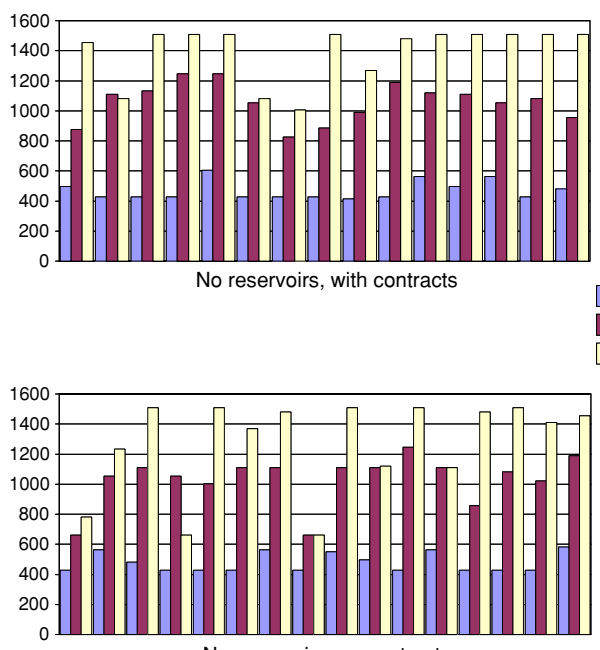

No reservoirs, no contracts
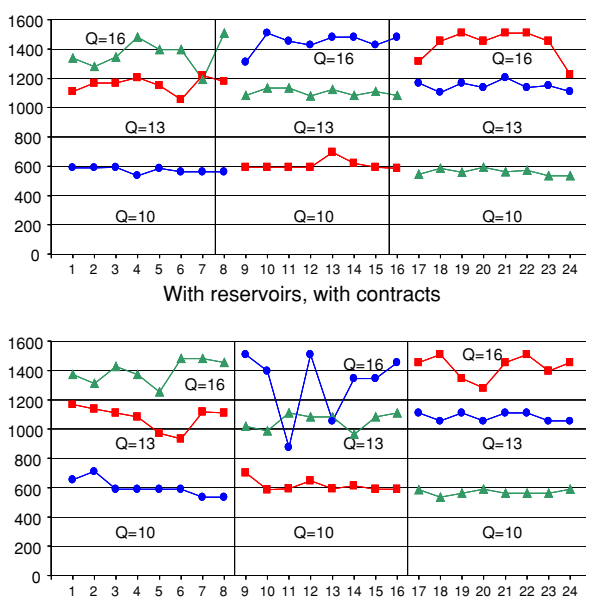

With reservoirs, no contracts
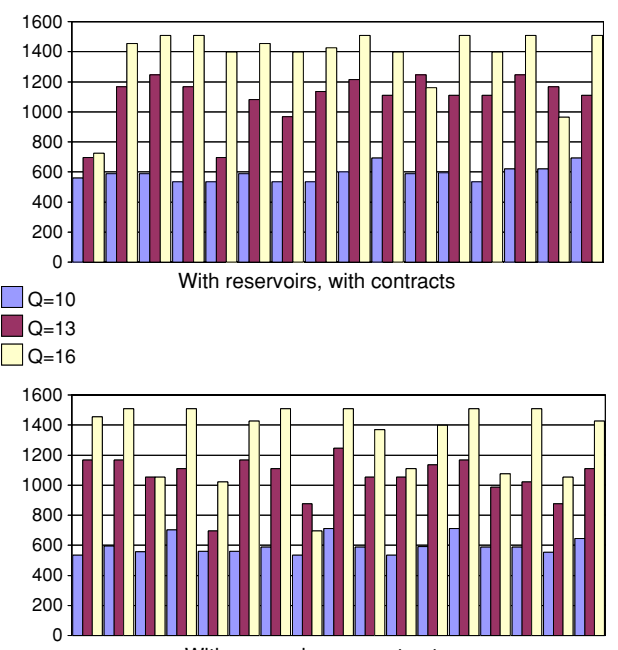

Fig. 5 Median total payoff across groups

There was indeed some sampling variation across the between 15 and 17 independent observations in each treatment. Figure 5 shows the median total payoff a group of three experimental countries obtained over the eight rounds in which they played each inflow. Variation is lowest with low inflow $(\mathrm{Q}=10)$, where the noncooperative outcome is most predominant. For normal and high water settings variation is higher. Some triplets achieved some degree of cooperation, others did not. Note that even though cooperation was relatively easy in high water years, some groups of countries fall short of the achievable total payoff. Individual variations like these dominate possible treatment effects, such that overall differences between treatments cannot be detected.

Footnote 21 continued

for the same cohort of individuals. This is also the case for the lines with the quadratic (red) and triangular (green) markers. 


\section{Summary and Conclusions}

We examined the likely impact of new Uzbek reservoirs on the Syr Darya economies. This impact crucially depends on two issues. First, the reservoirs change the seasonal distribution of water availability in downstream Uzbekistan and Kazakhstan for any given release by Kyrgyzstan. Thus, payoffs from Kyrgyz water releases to the three countries have to be re-estimated. Secondly, the changed parameters may change the likelihood of regional cooperation. We designed a strategic game to address these issues. Costs and benefits of water releases were computed using data from the region. We then set up a laboratory experiment to examine the behavioural properties of the river sharing problem.

The theoretical analysis reveals that regional cooperation is still required for basinwide net benefits to be maximised. In this sense the reservoirs do not achieve the goal of Uzbek selfsufficiency. The experimental results strongly suggest that failure to cooperate is systematic. Inefficient noncooperative outcomes prevail in our experiments, in line with past behaviour in the river conflict, but in contrast to most trust games reported in the experimental literature. Experimental participants fail to set up mutually beneficial agreements (particularly in lowwater years) and if agreements are made they are frequently broken. Thus our results suggest that failure to implement cooperative agreements should not be attributed to current decision makers' unwillingness alone. Cooperation failure is inherent to the structural features of the river conflict. Thus our results leave us pessimistic about decision makers being able to play the game more cooperatively in the future. Rather, they suggest changing the structure of the game, notably the sequence of water release and compensation that appears to make cooperation so difficult. While there are physical limits to synchronising water release and compensation in a barter scheme (due to prohibitive storage costs of energy and fuel), instalment schemes using money payments may help to reduce the risks to trustful behaviour. ${ }^{22}$ Once these mechanisms are developed, new experiments can be designed to test their likely effectiveness.

The enhanced basinwide efficiency effect of the new reservoirs originates mainly from Uzbekistan's reduced dependency on Kyrgyz summer releases, and is limited to low-water years. A possible effect of enhanced cooperation can be detected statistically, but it is relatively small. As an overall effect of the new reservoirs we observe a median efficiency gain of the equivalent of an annual US\$ 16.1 million for the low-water years, and no significant effect for normal and high-water years. Though this figure can naturally not be precise, it may provide an order of magnitude for a cost-benefit analysis of constructing the reservoirs. The benefits need to be weighed against the high construction costs. For these no official Uzbek figures are available, but they are estimated in the order of several hundred million dollars.

Of course, our findings have their limits. Though we have made every effort to trace the real economic framework as accurately as possible, no economic model (experimental or theoretical) can guarantee that no salient features of the real situation are lost or distorted when simplifying the economic environment. Undeniably the laboratory environment adds some artificiality as well. Despite these caveats we believe that the experimental methodology widens the scope for economic case studies, when behavioural influences are known to be relevant but natural data are unavailable.

Further, for the first experimental study on the Syr Darya river conflict we had to restrict the analysis to a few representative scenarios. Many future developments are uncertain today. In the long run, population growth, economic development, or world market conditions for

22 In this sense, our data call for a further development of a 'letter of credit' scheme like the one suggested in World Bank (2004a). 
cotton may alter the parameters of the game. There are also worries that the glaciers and snowfields that feed the Syr Darya will shrink because of climate change. As a consequence, inflow would rise in the short run (because the melting water is added to the natural inflow), but fall in the long run (as glaciers are depleted). ${ }^{23}$ This increased scarcity of water could reinforce the conflict in the future.

The relevant long-term future scenarios are also affected by strategic decisions outside our economic analysis. If construction plans for the Kambarata I and II hydropower plants in the Kyrgyz mountains are eventually realised an entirely different situation would arise. Kyrgyzstan would be able to generate an electricity surplus in winter, and use the Toktogul reservoir to re-regulate the Naryn river flow towards an irrigation mode. The Kambarata hydropower stations, however, are projects of a magnitude that Kyrgyzstan cannot shoulder on its own (estimates are in excess of US\$2bn), and existing cost-effectiveness analyses question their economic viability. Nevertheless, both Russia and Kazakhstan have shown an interest in co-financing the projects (possibly to gain political influence in the region) and further research is needed should these plans materialise.

While the set-up of the present experiment has been tailored to the Syr Darya river conflict, the methodology introduced is applicable to many other transboundary river conflicts as well. The other great Central Asian river, the Amu Darya, has characteristics that could turn the river into exactly the same problem as the Syr Darya, if upstream Tajikistan proceeds with plans to expand its hydropower capacity. In light of the Syr Darya experience, downstream Uzbekistan and Turkmenistan are seriously concerned that the conflict there may be replicated. On the river Nile there is potential for conflict if upstream Ethiopia decides to develop its substantial hydropower potential thus disrupting the growing season in Egypt. Namibian plans for the Popa Falls hydropower plant on the Okavango river potentially affect wildlifeoriented tourism in Botswana's national parks in the downstream Okavango delta. All these examples share a potential conflict between hydropower in an upstream country and other economic interests in another downstream country. In future it is likely that more conflicts will emerge since only $10 \%$ of the world's hydropower potential is currently being exploited (Khagram 2004). This source of energy can therefore be expected to play a much greater role than today, and management of the resulting water conflicts becomes an even more vital issue.

Open Access This article is distributed under the terms of the Creative Commons Attribution Noncommercial License which permits any noncommercial use, distribution, and reproduction in any medium, provided the original author(s) and source are credited.

\section{Appendix A. Estimation of the Payoff Functions}

\section{A.1. Kyrgyzstan}

Electricity output in the summer season, $\mathrm{Y}^{\mathrm{s}} \mathrm{MWh}$, is given by the hydropower production function:

$$
\mathrm{Y}^{\mathrm{S}}=\alpha \mathrm{q}_{\mathrm{ky}}^{\mathrm{s}}
$$

where $\alpha>0$ is a productivity parameter and $\mathrm{q}_{\mathrm{ky}}^{\mathrm{s}} \mathrm{BCM}$ is the Kyrgyz water release from the Toktogul Reservoir in the summer season. Kyrgyzstan must cover a domestic energy demand

23 According to current estimates the volume of glaciers on the territory of Kyrgyzstan will reduce significantly over the next quarter of a century resulting in a considerable reduction of water in the region's rivers (see for example IPPC 2001). 
of $\mathrm{E}^{\mathrm{s}} \mathrm{MWh}$ in summer. Due to technical losses, the necessary gross power generation necessary is given by $\mathrm{E}^{\mathrm{s}} / \nu^{\mathrm{s}} \mathrm{MWh}$, where $v^{\mathrm{s}} \in[0 ; 1]$ is an efficiency parameter. The Kyrgyz domestic energy deficit in the summer season, $\mathrm{D}^{\mathrm{s}} \mathrm{MWh}$, is defined as follows:

$$
\mathrm{D}^{\mathrm{s}}=\mathrm{E}^{\mathrm{s}} / \nu^{\mathrm{s}}-\alpha \mathrm{q}_{\mathrm{ky}}^{\mathrm{s}}
$$

To cover this deficit Kyrgyzstan operates its thermal power plant, Bishkek I, fuelled by imported natural gas and coal. Bishkek I has a short-run marginal cost of $C_{I} U S \$ / k w h$ and an operating capacity of K MWh. If the domestic energy deficit is larger than the capacity of Bishkek I, a second thermal power plant, Bishkek II, is operated. It has a short-run marginal cost of $\mathrm{C}_{\mathrm{II}}>\mathrm{C}_{\mathrm{I}}$ and an assumed unlimited capacity within the relevant range of the model. Conversely, in the case of a domestic energy surplus, Kyrgyz electricity is exported to Uzbekistan and Kazakhstan. Electricity payments are not modelled explicitly, but may implicitly constitute a part of the side payments between countries. The Kyrgyz gross payoff during summer (excluding side payments), measured in million US\$, is given as follows:

$$
\begin{aligned}
& \pi_{\mathrm{ky}}^{\mathrm{s}}=-\mathrm{MIN}\left\{\mathrm{C}_{\mathrm{I}} \mathrm{D}^{\mathrm{s}}, 0\right\} \quad \text { for } \mathrm{D}^{\mathrm{s}} \leq \mathrm{K} \\
& \pi_{\mathrm{ky}}^{\mathrm{s}}=-\mathrm{C}_{\mathrm{I}} \mathrm{K}-\mathrm{C}_{\mathrm{II}}\left(\mathrm{D}^{\mathrm{s}}-\mathrm{K}\right) \quad \text { for } \mathrm{D}^{\mathrm{s}}>\mathrm{K} .
\end{aligned}
$$

In winter, hydropower is produced using the same constant-returns-to-scale technology as expressed in (1). Denoting all seasonal variables by superscript $w$, the Kyrgyz domestic energy deficit in winter is given by:

$$
\mathrm{D}^{\mathrm{w}}=\mathrm{E}^{\mathrm{w}} / \nu^{\mathrm{w}}-\alpha \mathrm{q}_{\mathrm{ky}}^{\mathrm{w}}
$$

A domestic energy deficit is covered by the Bishkek I and II thermal power plants in the same manner as in the summer period. In case of a domestic energy surplus, Kyrgyzstan is assumed to have no export markets in the winter period. The Kyrgyz gross payoff in winter is written:

$$
\begin{aligned}
& \pi_{\mathrm{ky}}^{\mathrm{W}}=-\mathrm{MIN}\left\{\mathrm{C}_{\mathrm{I}} \mathrm{D}^{\mathrm{w}}, 0\right\} \quad \text { for } \mathrm{D}^{\mathrm{W}} \leq \mathrm{K} \\
& \pi_{\mathrm{ky}}^{\mathrm{W}}=-\mathrm{C}_{\mathrm{I}} \mathrm{K}-\mathrm{C}_{\mathrm{II}}\left(\mathrm{D}^{\mathrm{w}}-\mathrm{K}\right) \quad \text { for } \mathrm{D}^{\mathrm{w}}>\mathrm{K}
\end{aligned}
$$

Denoting the side payment received by Kyrgyzstan from Uzbekistan for its water and electricity services by $S_{\mathrm{ky}}$ the Kyrgyz total payoff (in million US\$) is ${ }^{24}$ :

$$
\pi_{\mathrm{ky}}=\mathrm{I}_{\mathrm{ky}}+\pi_{\mathrm{ky}}^{\mathrm{s}}+\pi_{\mathrm{ky}}^{\mathrm{w}}+\mathrm{S}_{\mathrm{ky}}
$$

The intercept of the payoff function, $\mathrm{I}_{\mathrm{ky}}$, is not specified and can be chosen arbitrarily, since our economic analysis only aims at comparing payoffs in different scenarios. If it is omitted, then a zero Kyrgyz payoff corresponds to a situation in which the domestic energy deficit is non-negative in both seasons.

\section{A.2. Uzbekistan}

Uzbek payoff relates only to the summer period and can be divided into two components: irrigation and electricity. Uzbek irrigation supply for cotton production is available from two main sources: summer water released by Kyrgyzstan, $\mathrm{q}_{\mathrm{ky}}^{\mathrm{s}}$, and water available in the new

24 In the model, Kazakhstan does not issue a side payment directly to Kyrgyzstan (as it does in reality), but rather to Uzbekistan. This is done to ensure that Uzbekistan has an incentive to release water to Kazakhstan. In reality, the Uzbek incentive to release water to Kazakhstan is mainly political, i.e. Uzbekistan does not want to upset international relations with its downstream neighbour. 
Uzbek reservoirs, $\mathrm{R}$, which are filled in the winter period where $\mathrm{R}<\mathrm{q}_{\mathrm{ky}}^{\mathrm{W}}$. Uzbekistan releases some of this water to Kazakhstan, $\mathrm{q}_{\mathrm{uz}} \leq \mathrm{q}_{\mathrm{ky}}^{\mathrm{s}}+\mathrm{R}$, and withdraws the residual, $\mathrm{q}_{\mathrm{ky}}^{\mathrm{s}}+\mathrm{R}-\mathrm{q}_{\mathrm{uz}}$, for cotton production. Of its total water withdrawals, only a share $0 \leq \beta_{\mathrm{uz}} \leq 1$ is used for cotton irrigation with the residual $\left(1-\beta_{\mathrm{uz}}\right)$ used for other crops, the production of which is assumed non-profitable. The economic value of irrigation water for cotton production is P US\$/KCM. While we have not explicitly modelled an agricultural production function, it would be unrealistic to expect that marginal benefits are always positive, especially for high levels of water input. It is therefore assumed that if irrigation input reaches an optimum point, $\mathrm{O}_{\mathrm{uz}}$, then the marginal value of irrigation water is zero. ${ }^{25}$ Uzbek gross irrigation benefits (in million US\$) are thus written:

$$
\mathrm{P} \beta_{\mathrm{uz}} \mathrm{MIN}\left\{\left(\mathrm{q}_{\mathrm{ky}}^{\mathrm{s}}+\mathrm{R}\right)-\mathrm{q}_{\mathrm{uz}}, \mathrm{O}_{\mathrm{uz}}\right\}
$$

We now turn to the Uzbek electricity benefits. Suppose that Kyrgyzstan runs a domestic energy surplus in summer and that a share of this surplus is exported to Uzbekistan. In this case Uzbekistan can import electricity at a lower cost than were it to produce this electricity domestically. The gross benefit of electricity imports is valued at the opportunity cost of operating a coal fired power plant in Uzbekistan, the short-run marginal cost of which is $\mathrm{C}_{\mathrm{uz}} \mathrm{US} \$ \mathrm{kwh}$. After accounting for the technical loss of transmitting electricity through the Uzbek power grid, electricity available for import equals $-\rho \mathrm{D}^{\mathrm{S}}$, where $0 \leq \rho \leq 1$ is an efficiency parameter. Due to technical constraints in the transmission grid, electricity exports cannot exceed X MWh. The exported electricity is shared between Uzbekistan and Kazakhstan. Denoting Uzbekistan's share by $0 \leq \gamma \leq 1$, its electricity benefits are:

$$
\operatorname{MAX}\left\{\mathrm{C}_{\mathrm{uz}} \gamma \rho \operatorname{MIN}\left\{-\mathrm{D}^{\mathrm{s}}, \mathrm{X}\right\}, 0\right\}
$$

Denoting the side payment from Kazakhstan to Uzbekistan, $S_{\mathrm{uz}}$ we can write the Uzbek payoff as follows:

$$
\begin{aligned}
\pi_{\mathrm{uz}}= & \mathrm{I}_{\mathrm{uz}}+\mathrm{P} \beta_{\mathrm{uz}} \mathrm{MIN}\left\{\left(\mathrm{q}_{\mathrm{ky}}^{\mathrm{s}}+\mathrm{R}\right)-\mathrm{q}_{\mathrm{uz}}, \mathrm{O}_{\mathrm{uz}}\right\}+\operatorname{MAX}\left\{\mathrm{C}_{\mathrm{uz}} \gamma \rho \mathrm{MIN}\left\{-\mathrm{D}^{\mathrm{s}}, \mathrm{X}\right\}, 0\right\} \\
& +\mathrm{S}_{\mathrm{uz}}-\mathrm{S}_{\mathrm{ky}}
\end{aligned}
$$

As with the Kyrgyz payoff function the intercept does not have any meaningful interpretation. If intercept and side payments are omitted and $\mathrm{R}=0$ then a zero payoff would correspond to a situation in which Kyrgyzstan releases no water at all in summer.

\section{A.3. Kazakhstan}

Like Uzbekistan, Kazakhstan also benefits from irrigation and electricity in the summer period. The Kazakh payoff-function is similar to that of Uzbekistan and is given by the following expression (where Kazakh variables are denoted with subscript $k a$ )

$$
\pi_{\mathrm{ka}}=\mathrm{I}_{\mathrm{ka}}+\mathrm{P} \beta_{\mathrm{ka}} \mathrm{MIN}\left\{\mathrm{q}_{\mathrm{uz}}, \mathrm{O}_{\mathrm{ka}}\right\}+\operatorname{MAX}\left\{\mathrm{C}_{\mathrm{ka}}(1-\gamma) \rho \mathrm{MIN}\left\{-\mathrm{D}^{\mathrm{s}}, \mathrm{X}\right\}, 0\right\}-\mathrm{S}_{\mathrm{uz}}
$$

where $\mathrm{I}_{\mathrm{ka}}$ is the unspecified intercept of the Kazakh payoff function.

25 Clearly this represents a substantial simplification of a more realistic cotton production function with diminishing returns to scale (and possibly a negative marginal product). The practical significance of this for the experimental results, however, seems negligible. 
Table 7 Historical flow data (BCM), Toktogul Reservoir, 1988-2003

\begin{tabular}{|c|c|c|c|c|c|c|}
\hline \multirow[t]{2}{*}{ Year } & \multicolumn{2}{|l|}{ Total } & \multicolumn{2}{|c|}{ Summer } & \multicolumn{2}{|l|}{ Winter } \\
\hline & Inflow & Outflow & Inflow & Outflow & Inflow & Outflow \\
\hline 1988 & 16.52 & 12.24 & 13.46 & 8.80 & 3.06 & 3.44 \\
\hline 1989 & 10.13 & 14.97 & 7.34 & 10.97 & 2.79 & 4.00 \\
\hline 1990 & 12.99 & 11.60 & 10.25 & 7.09 & 2.74 & 4.51 \\
\hline 1991 & 10.74 & 13.16 & 7.93 & 8.51 & 2.81 & 4.65 \\
\hline 1992 & 12.05 & 12.19 & 9.05 & 6.55 & 3.00 & 5.64 \\
\hline 1993 & 13.64 & 10.59 & 10.61 & 4.41 & 3.03 & 6.18 \\
\hline 1994 & 15.24 & 14.52 & 12.08 & 6.72 & 3.16 & 7.80 \\
\hline 1995 & 10.89 & 14.62 & 7.88 & 6.33 & 3.01 & 8.29 \\
\hline 1996 & 13.70 & 14.53 & 10.94 & 6.16 & 2.76 & 8.37 \\
\hline 1997 & 10.83 & 13.68 & 8.09 & 6.08 & 2.74 & 7.60 \\
\hline 1998 & 14.49 & 11.16 & 11.50 & 3.68 & 2.99 & 7.48 \\
\hline 1999 & 14.47 & 13.47 & 11.01 & 5.07 & 3.46 & 8.40 \\
\hline 2000 & 12.62 & 15.18 & 9.19 & 6.48 & 3.43 & 8.70 \\
\hline 2001 & 12.56 & 15.15 & 9.29 & 5.91 & 3.27 & 9.24 \\
\hline 2002 & 16.67 & 11.38 & 13.51 & 3.65 & 3.16 & 7.73 \\
\hline 2003 & 15.67 & 14.16 & 12.00 & 4.90 & 3.67 & 9.26 \\
\hline Average & 13.33 & 13.29 & 10.26 & 6.33 & 3.07 & 6.96 \\
\hline Percentage (\%) & 100 & 100 & 77.0 & 47.7 & 23.0 & 52.3 \\
\hline Minimum & 10.13 & 10.59 & 7.34 & 3.65 & 2.74 & 3.44 \\
\hline Maximum & 16.67 & 15.18 & 13.51 & 10.97 & 3.67 & 9.26 \\
\hline Standard deviation & 2.09 & 1.56 & 1.96 & 1.91 & 0.28 & 1.94 \\
\hline
\end{tabular}

Source: Primary data provided by JSC Kyrgyzenergo, Bishkek

\section{A.4. The Underlying Data}

Having defined the payoff functions of the three riparians the next step is to use real data to estimate the model. Analytically, this procedure is straightforward since it simply involves the use of numerical values for all exogenous variables and parameters. In practical terms, however, the compilation and selection of relevant data constituted a significant challenge.

Water availability is a key determinant of riparian payoff. We use primary data collected by JSC Kyrgyzenergo for the 1988-2003 period (see Table 7). Water inflow is a stochastic variable determined by nature while water outflow is a reflection of political decisions made by Kyrgyzstan. The presence of what is, in effect, two stochastic variables (summer and winter inflows) adds complications to the experimental design. We thus make the simplifying assumption that Kyrgyz winter release is residually determined, $\mathrm{q}_{\mathrm{ky}}^{\mathrm{w}}=\mathrm{Q}-\mathrm{q}_{\mathrm{ky}}^{\mathrm{s}}$ where $\mathrm{Q}$ denotes annual inflow. ${ }^{26}$ This is equivalent to assuming that annual inflow equals annual outflow. While this is true in the medium to long term it is a restrictive assumption on an annual basis. Thus while in practice the Toktogul Reservoir is large enough to enable multi-annual regulation, our analysis focuses exclusively on the seasonal conflict.

26 Ambec and Doucet (2003) and Moller (2005a, b) make similar assumptions. 
Table 8 Assumed values of exogenous variables and parameters

\begin{tabular}{|c|c|c|c|c|}
\hline Name & Description & Unit & Value & Source \\
\hline$\alpha$ & Hydropower efficiency & $\mathrm{m}^{3} / \mathrm{kWh}$ & 0.86 & Antipova et al. (2002) \\
\hline $\mathrm{E}^{\mathrm{S}}$ & Net energy demand, summer & GWh & 2,550 & World Bank (2004a) \\
\hline $\mathrm{E}^{\mathrm{W}}$ & Net energy demand, winter & GWh & 4,950 & World Bank (2004a) \\
\hline$v^{\mathrm{S}}$ & Technical transmission efficiency, summer & percent & 90.0 & World Bank (2004a) \\
\hline$v^{\mathrm{W}}$ & Technical transmission efficiency, winter & percent & 85.0 & World Bank (2004a) \\
\hline K & Generation capacity, Bishkek I & GWh & 876 & World Bank (2004a) \\
\hline $\mathrm{C}^{\mathrm{I}}$ & Short-run marginal cost, Bishkek I & US\$/kWh & 0.0150 & World Bank (2004a) \\
\hline $\mathrm{C}^{\mathrm{II}}$ & Short-run marginal cost, Bishkek II & US\$/kWh & 0.0255 & World Bank (2004b) \\
\hline $\mathrm{C}_{\mathrm{uz}}$ & Short-run marginal cost, Uzbekistan & $\mathrm{US} \$ / \mathrm{kWh}$ & 0.0230 & World Bank (2004a) \\
\hline $\mathrm{C}_{\mathrm{ka}}$ & Short-run marginal cost, Kazakhstan & $\mathrm{US} \$ / \mathrm{kWh}$ & 0.0210 & World Bank (2004a) \\
\hline$\rho$ & Technical transmission efficiency, exports & percent & 94.0 & World Bank (2004a) \\
\hline$\gamma$ & Share of electricity exported to Uzbekistan & percent & 50.0 & World Bank (2004a) \\
\hline $\mathrm{X}$ & Maximum hydropower export volume & GWh & 4,000 & $\begin{array}{l}\text { Peter Graham (personal } \\
\text { communication, 2005) }^{\mathrm{a}}\end{array}$ \\
\hline $\mathrm{P}$ & Economic value of irrigation water & US\$/KCM & 20 & World Bank (2004a) \\
\hline $\mathrm{O}_{\mathrm{uz}}$ & Optimal irrigation input for Uzbekistan & $\mathrm{BCM}$ & 4.5 & $\begin{array}{l}\text { World Bank (2004a), } \\
\text { Antipova et al. (2002) }\end{array}$ \\
\hline $\mathrm{O}_{\mathrm{ka}}$ & Optimal irrigation input for Kazakhstan & $\mathrm{BCM}$ & 2.0 & $\begin{array}{l}\text { World Bank (2004a), } \\
\text { Antipova et al. (2002) }\end{array}$ \\
\hline
\end{tabular}

a Peter Graham, Tariff Policy \& Utility Reform Project, DFID Bishkek (personal communication, 9 February 2005)

Table 8 summarises the assumed values of the remaining exogenous variables and parameters a few of which deserve special mention: First, we have set the economic value of irrigation water at US\$ $20 / \mathrm{KCM}\left(1,000 \mathrm{~cm}^{3}\right)$. According to the World Bank (2004a), the value of irrigation in Central Asia is estimated as being in the region of $\$ 20-\$ 50$ per KCM. To produce conservative benefit estimates we choose the lower range of this estimate. Secondly, optimal irrigation input has been calculated on the basis of total land under cotton in Uzbekistan and Kazakhstan, including additional land introduced in the medium term. Our results are consistent with those provided by Antipova et al. (2002) who estimate a total downstream irrigation need of 6.5 BCM. Thirdly, to capture the effect of increased marginal cost of thermal power production beyond the capacity of Bishkek I, we used cost figures for Bishkek II. The Bishkek II plant, however, currently exists only at the design stage and although it could be completed within a few years the Kyrgyz government is yet to approve its construction. ${ }^{27}$

\section{Appendix B. The Payoff Tables}

See Tables 9, 10,11,12,13 and 14.

27 The Kyrgyz government hesitates to do so because the plant relies on imported natural gas from Uzbekistan. 
Table 9 Payoff table for $\mathrm{Q}=10$ without Uzbek reservoirs

\begin{tabular}{|c|c|c|c|c|c|}
\hline $\begin{array}{l}\text { Units passed } \\
\text { by player } 1\end{array}$ & $\begin{array}{l}\text { Units passed } \\
\text { by player } 2\end{array}$ & $\begin{array}{l}\text { Player 1's } \\
\text { payoff }\end{array}$ & $\begin{array}{l}\text { Player 2's } \\
\text { payoff }\end{array}$ & $\begin{array}{l}\text { Player 3's } \\
\text { payoff }\end{array}$ & Total payoff \\
\hline 3 & 0 & 333 & 12 & 83 & 428 \\
\hline 3 & 1 & 333 & -58 & 139 & 414 \\
\hline 3 & 2 & 333 & -128 & 195 & 400 \\
\hline 3 & 3 & 333 & -198 & 195 & 330 \\
\hline 4 & 0 & 272 & 148 & 144 & 564 \\
\hline 4 & 1 & 272 & 78 & 200 & 55 \\
\hline 4 & 2 & 272 & 8 & 256 & 536 \\
\hline 4 & 3 & 272 & -62 & 256 & 466 \\
\hline 4 & 4 & 272 & -132 & 256 & 396 \\
\hline 5 & 0 & 76 & 277 & 229 & 582 \\
\hline 5 & 1 & 76 & 242 & 285 & 603 \\
\hline 5 & 2 & 76 & 172 & 341 & 589 \\
\hline 5 & 3 & 76 & 102 & 341 & 519 \\
\hline 5 & 4 & 76 & 32 & 341 & 449 \\
\hline 5 & 5 & 76 & -38 & 341 & 379 \\
\hline 6 & 0 & -144 & 370 & 314 & 540 \\
\hline 6 & 1 & -144 & 370 & 370 & 596 \\
\hline 6 & 2 & -144 & 335 & 426 & 617 \\
\hline 6 & 3 & -144 & 265 & 426 & 547 \\
\hline 6 & 4 & -144 & 195 & 426 & 477 \\
\hline 6 & 5 & -144 & 125 & 426 & 407 \\
\hline 6 & 6 & -144 & 55 & 426 & 337 \\
\hline 7 & 0 & -364 & 463 & 399 & 498 \\
\hline 7 & 1 & -364 & 463 & 455 & 554 \\
\hline 7 & 2 & -364 & 463 & 511 & 610 \\
\hline 7 & 3 & -364 & 428 & 511 & 575 \\
\hline 7 & 4 & -364 & 358 & 511 & 505 \\
\hline 7 & 5 & -364 & 288 & 511 & 435 \\
\hline 7 & 6 & -364 & 218 & 511 & 365 \\
\hline 7 & 7 & -364 & 148 & 511 & 295 \\
\hline 8 & 0 & -583 & 549 & 478 & 444 \\
\hline 8 & 1 & -583 & 549 & 534 & 500 \\
\hline 8 & 2 & -583 & 549 & 590 & 556 \\
\hline 8 & 3 & -583 & 549 & 590 & 556 \\
\hline 8 & 4 & -583 & 514 & 590 & 521 \\
\hline 8 & 5 & -583 & 444 & 590 & 451 \\
\hline 8 & 6 & -583 & 374 & 590 & 381 \\
\hline 8 & 7 & -583 & 304 & 590 & 311 \\
\hline 8 & 8 & -583 & 234 & 590 & 241 \\
\hline 9 & 0 & -803 & 549 & 478 & 224 \\
\hline 9 & 1 & -803 & 549 & 534 & 280 \\
\hline 9 & 2 & -803 & 549 & 590 & 336 \\
\hline 9 & 3 & -803 & 549 & 590 & 336 \\
\hline 9 & 4 & -803 & 549 & 590 & 336 \\
\hline 9 & 5 & -803 & 514 & 590 & 301 \\
\hline 9 & 6 & -803 & 444 & 590 & 231 \\
\hline 9 & 7 & -803 & 374 & 590 & 161 \\
\hline 9 & 8 & -803 & 304 & 590 & 91 \\
\hline 9 & 9 & -803 & 234 & 590 & 21 \\
\hline
\end{tabular}


Table 10 Payoff table for $\mathrm{Q}=10$ with Uzbek reservoirs

\begin{tabular}{|c|c|c|c|c|c|}
\hline $\begin{array}{l}\text { Units passed } \\
\text { by player } 1\end{array}$ & $\begin{array}{l}\text { Units passed } \\
\text { by player } 2\end{array}$ & $\begin{array}{l}\text { Player 1's } \\
\text { payoff }\end{array}$ & $\begin{array}{l}\text { Player 2's } \\
\text { payoff }\end{array}$ & $\begin{array}{l}\text { Player 3's } \\
\text { payoff }\end{array}$ & Total payoff \\
\hline 3 & 0 & 333 & 117 & 83 & 533 \\
\hline 3 & 1 & 333 & 117 & 139 & 589 \\
\hline 3 & 2 & 333 & 47 & 195 & 575 \\
\hline 3 & 3 & 333 & -23 & 195 & 505 \\
\hline 4 & 0 & 272 & 183 & 144 & 599 \\
\hline 4 & 1 & 272 & 183 & 200 & 655 \\
\hline 4 & 2 & 272 & 183 & 256 & 711 \\
\hline 4 & 3 & 272 & 113 & 256 & 641 \\
\hline 4 & 4 & 272 & 43 & 256 & 571 \\
\hline 5 & 0 & 76 & 277 & 229 & 582 \\
\hline 5 & 1 & 76 & 277 & 285 & 638 \\
\hline 5 & 2 & 76 & 277 & 341 & 694 \\
\hline 5 & 3 & 76 & 277 & 341 & 694 \\
\hline 5 & 4 & 76 & 207 & 341 & 624 \\
\hline 5 & 5 & 76 & 137 & 341 & 554 \\
\hline 6 & 0 & -144 & 370 & 314 & 540 \\
\hline 6 & 1 & -144 & 370 & 370 & 596 \\
\hline 6 & 2 & -144 & 370 & 426 & 652 \\
\hline 6 & 3 & -144 & 370 & 426 & 652 \\
\hline 6 & 4 & -144 & 370 & 426 & 652 \\
\hline 6 & 5 & -144 & 300 & 426 & 582 \\
\hline 6 & 6 & -144 & 230 & 426 & 512 \\
\hline 7 & 0 & -364 & 463 & 399 & 498 \\
\hline 7 & 1 & -364 & 463 & 455 & 554 \\
\hline 7 & 2 & -364 & 463 & 511 & 610 \\
\hline 7 & 3 & -364 & 463 & 511 & 610 \\
\hline 7 & 4 & -364 & 463 & 511 & 610 \\
\hline 7 & 5 & -364 & 463 & 511 & 610 \\
\hline 7 & 6 & -364 & 393 & 511 & 540 \\
\hline 7 & 7 & -364 & 323 & 511 & 470 \\
\hline 8 & 0 & -583 & 549 & 478 & 444 \\
\hline 8 & 1 & -583 & 549 & 534 & 500 \\
\hline 8 & 2 & -583 & 549 & 590 & 556 \\
\hline 8 & 3 & -583 & 549 & 590 & 556 \\
\hline 8 & 4 & -583 & 549 & 590 & 556 \\
\hline 8 & 5 & -583 & 549 & 590 & 556 \\
\hline 8 & 6 & -583 & 549 & 590 & 556 \\
\hline 8 & 7 & -583 & 479 & 590 & 486 \\
\hline 8 & 8 & -583 & 409 & 590 & 416 \\
\hline 9 & 0 & -803 & 549 & 478 & 224 \\
\hline 9 & 1 & -803 & 549 & 534 & 280 \\
\hline 9 & 2 & -803 & 549 & 590 & 336 \\
\hline 9 & 3 & -803 & 549 & 590 & 336 \\
\hline 9 & 4 & -803 & 549 & 590 & 336 \\
\hline 9 & 5 & -803 & 549 & 590 & 336 \\
\hline 9 & 6 & -803 & 549 & 590 & 336 \\
\hline 9 & 7 & -803 & 549 & 590 & 336 \\
\hline 9 & 8 & -803 & 479 & 590 & 266 \\
\hline 9 & 9 & -803 & 409 & 590 & 196 \\
\hline
\end{tabular}


Table 11 Payoff table for $\mathrm{Q}=13$ without Uzbek reservoirs

\begin{tabular}{|c|c|c|c|c|c|}
\hline $\begin{array}{l}\text { Units passed } \\
\text { by player } 1\end{array}$ & $\begin{array}{l}\text { Units passed } \\
\text { by player } 2\end{array}$ & $\begin{array}{l}\text { Player 1's } \\
\text { payoff }\end{array}$ & $\begin{array}{l}\text { Player 2's } \\
\text { payoff }\end{array}$ & $\begin{array}{l}\text { Player 3's } \\
\text { payoff }\end{array}$ & Total payoff \\
\hline 3 & 0 & 333 & 12 & 83 & 428 \\
\hline 3 & 1 & 333 & -58 & 139 & 414 \\
\hline 3 & 2 & 333 & -128 & 195 & 400 \\
\hline 3 & 3 & 333 & -198 & 195 & 330 \\
\hline 4 & 0 & 370 & 148 & 144 & 662 \\
\hline 4 & 1 & 370 & 78 & 200 & 648 \\
\hline 4 & 2 & 370 & 8 & 256 & 634 \\
\hline 4 & 3 & 370 & -62 & 256 & 564 \\
\hline 4 & 4 & 370 & -132 & 256 & 494 \\
\hline 5 & 0 & 370 & 277 & 229 & 876 \\
\hline 5 & 1 & 370 & 242 & 285 & 897 \\
\hline 5 & 2 & 370 & 172 & 341 & 883 \\
\hline 5 & 3 & 370 & 102 & 341 & 813 \\
\hline 5 & 4 & 370 & 32 & 341 & 743 \\
\hline 5 & 5 & 370 & -38 & 341 & 673 \\
\hline 6 & 0 & 370 & 370 & 314 & 1,054 \\
\hline 6 & 1 & 370 & 370 & 370 & 1,110 \\
\hline 6 & 2 & 370 & 335 & 426 & 1,131 \\
\hline 6 & 3 & 370 & 265 & 426 & 1,061 \\
\hline 6 & 4 & 370 & 195 & 426 & 991 \\
\hline 6 & 5 & 370 & 125 & 426 & 921 \\
\hline 6 & 6 & 370 & 55 & 426 & 851 \\
\hline 7 & 0 & 272 & 463 & 399 & 1,134 \\
\hline 7 & 1 & 272 & 463 & 455 & 1,190 \\
\hline 7 & 2 & 272 & 463 & 511 & 1,246 \\
\hline 7 & 3 & 272 & 428 & 511 & 1,211 \\
\hline 7 & 4 & 272 & 358 & 511 & 1,141 \\
\hline 7 & 5 & 272 & 288 & 511 & 1,071 \\
\hline 7 & 6 & 272 & 218 & 511 & 1,001 \\
\hline 7 & 7 & 272 & 148 & 511 & 931 \\
\hline 8 & 0 & 76 & 549 & 478 & 1,103 \\
\hline 8 & 1 & 76 & 549 & 534 & 1,159 \\
\hline 8 & 2 & 76 & 549 & 590 & 1,215 \\
\hline 8 & 3 & 76 & 549 & 590 & 1,215 \\
\hline 8 & 4 & 76 & 514 & 590 & 1,180 \\
\hline 8 & 5 & 76 & 444 & 590 & 1,110 \\
\hline 8 & 6 & 76 & 374 & 590 & 1,040 \\
\hline 8 & 7 & 76 & 304 & 590 & 970 \\
\hline 8 & 8 & 76 & 234 & 590 & 900 \\
\hline 9 & 0 & -144 & 549 & 478 & 883 \\
\hline 9 & 1 & -144 & 549 & 534 & 939 \\
\hline 9 & 2 & -144 & 549 & 590 & 995 \\
\hline 9 & 3 & -144 & 549 & 590 & 995 \\
\hline 9 & 4 & -144 & 549 & 590 & 995 \\
\hline 9 & 5 & -144 & 514 & 590 & 960 \\
\hline 9 & 6 & -144 & 444 & 590 & 890 \\
\hline 9 & 7 & -144 & 374 & 590 & 820 \\
\hline 9 & 8 & -144 & 304 & 590 & 750 \\
\hline 9 & 9 & -144 & 234 & 590 & 680 \\
\hline
\end{tabular}


Table 12 Payoff table for $\mathrm{Q}=13$ with Uzbek reservoirs

\begin{tabular}{|c|c|c|c|c|c|}
\hline $\begin{array}{l}\text { Units passed } \\
\text { by player } 1\end{array}$ & $\begin{array}{l}\text { Units passed } \\
\text { by player } 2\end{array}$ & $\begin{array}{l}\text { Player 1's } \\
\text { payoff }\end{array}$ & $\begin{array}{l}\text { Player 2's } \\
\text { payoff }\end{array}$ & $\begin{array}{l}\text { Player 3's } \\
\text { payoff }\end{array}$ & Total payoff \\
\hline 3 & 0 & 333 & 117 & 83 & 533 \\
\hline 3 & 1 & 333 & 117 & 139 & 589 \\
\hline 3 & 2 & 333 & 47 & 195 & 575 \\
\hline 3 & 3 & 333 & -23 & 195 & 505 \\
\hline 4 & 0 & 370 & 183 & 144 & 697 \\
\hline 4 & 1 & 370 & 183 & 200 & 753 \\
\hline 4 & 2 & 370 & 183 & 256 & 809 \\
\hline 4 & 3 & 370 & 113 & 256 & 739 \\
\hline 4 & 4 & 370 & 43 & 256 & 669 \\
\hline 5 & 0 & 370 & 277 & 229 & 876 \\
\hline 5 & 1 & 370 & 277 & 285 & 932 \\
\hline 5 & 2 & 370 & 277 & 341 & 988 \\
\hline 5 & 3 & 370 & 277 & 341 & 988 \\
\hline 5 & 4 & 370 & 207 & 341 & 918 \\
\hline 5 & 5 & 370 & 137 & 341 & 848 \\
\hline 6 & 0 & 370 & 370 & 314 & 1,054 \\
\hline 6 & 1 & 370 & 370 & 370 & 1,110 \\
\hline 6 & 2 & 370 & 370 & 426 & 1,166 \\
\hline 6 & 3 & 370 & 370 & 426 & 1,166 \\
\hline 6 & 4 & 370 & 370 & 426 & 1,166 \\
\hline 6 & 5 & 370 & 300 & 426 & 1,096 \\
\hline 6 & 6 & 370 & 230 & 426 & 1,026 \\
\hline 7 & 0 & 272 & 463 & 399 & 1,134 \\
\hline 7 & 1 & 272 & 463 & 455 & 1,190 \\
\hline 7 & 2 & 272 & 463 & 511 & 1,246 \\
\hline 7 & 3 & 272 & 463 & 511 & 1,246 \\
\hline 7 & 4 & 272 & 463 & 511 & 1,246 \\
\hline 7 & 5 & 272 & 463 & 511 & 1,246 \\
\hline 7 & 6 & 272 & 393 & 511 & 1,176 \\
\hline 7 & 7 & 272 & 323 & 511 & 1,106 \\
\hline 8 & 0 & 76 & 549 & 478 & 1,103 \\
\hline 8 & 1 & 76 & 549 & 534 & 1,159 \\
\hline 8 & 2 & 76 & 549 & 590 & 1,215 \\
\hline 8 & 3 & 76 & 549 & 590 & 1,215 \\
\hline 8 & 4 & 76 & 549 & 590 & 1,215 \\
\hline 8 & 5 & 76 & 549 & 590 & 1,215 \\
\hline 8 & 6 & 76 & 549 & 590 & 1,215 \\
\hline 8 & 7 & 76 & 479 & 590 & 1,145 \\
\hline 8 & 8 & 76 & 409 & 590 & 1,075 \\
\hline 9 & 0 & -144 & 549 & 478 & 883 \\
\hline 9 & 1 & -144 & 549 & 534 & 939 \\
\hline 9 & 2 & -144 & 549 & 590 & 995 \\
\hline 9 & 3 & -144 & 549 & 590 & 995 \\
\hline 9 & 4 & -144 & 549 & 590 & 995 \\
\hline 9 & 5 & -144 & 549 & 590 & 995 \\
\hline 9 & 6 & -144 & 549 & 590 & 995 \\
\hline 9 & 7 & -144 & 549 & 590 & 995 \\
\hline 9 & 8 & -144 & 479 & 590 & 925 \\
\hline 9 & 9 & -144 & 409 & 590 & 855 \\
\hline
\end{tabular}


Table 13 Payoff table for $\mathrm{Q}=16$ without Uzbek reservoirs

\begin{tabular}{|c|c|c|c|c|c|}
\hline $\begin{array}{l}\text { Units passed } \\
\text { by player } 1\end{array}$ & $\begin{array}{l}\text { Units passed } \\
\text { by player } 2\end{array}$ & $\begin{array}{l}\text { Player 1's } \\
\text { payoff }\end{array}$ & $\begin{array}{l}\text { Player 2's } \\
\text { payoff }\end{array}$ & $\begin{array}{l}\text { Player 3's } \\
\text { payoff }\end{array}$ & Total payoff \\
\hline 3 & 0 & 333 & 12 & 83 & 428 \\
\hline 3 & 1 & 333 & -58 & 139 & 414 \\
\hline 3 & 2 & 333 & -128 & 195 & 400 \\
\hline 3 & 3 & 333 & -198 & 195 & 330 \\
\hline 4 & 0 & 370 & 148 & 144 & 662 \\
\hline 4 & 1 & 370 & 78 & 200 & 648 \\
\hline 4 & 2 & 370 & 8 & 256 & 634 \\
\hline 4 & 3 & 370 & -62 & 256 & 564 \\
\hline 4 & 4 & 370 & -132 & 256 & 494 \\
\hline 5 & 0 & 370 & 277 & 229 & 876 \\
\hline 5 & 1 & 370 & 242 & 285 & 897 \\
\hline 5 & 2 & 370 & 172 & 341 & 883 \\
\hline 5 & 3 & 370 & 102 & 341 & 813 \\
\hline 5 & 4 & 370 & 32 & 341 & 743 \\
\hline 5 & 5 & 370 & -38 & 341 & 673 \\
\hline 6 & 0 & 370 & 370 & 314 & 1,054 \\
\hline 6 & 1 & 370 & 370 & 370 & 1,110 \\
\hline 6 & 2 & 370 & 335 & 426 & 1,131 \\
\hline 6 & 3 & 370 & 265 & 426 & 1,061 \\
\hline 6 & 4 & 370 & 195 & 426 & 991 \\
\hline 6 & 5 & 370 & 125 & 426 & 921 \\
\hline 6 & 6 & 370 & 55 & 426 & 851 \\
\hline 7 & 0 & 370 & 463 & 399 & 1,232 \\
\hline 7 & 1 & 370 & 463 & 455 & 1,288 \\
\hline 7 & 2 & 370 & 463 & 511 & 1,344 \\
\hline 7 & 3 & 370 & 428 & 511 & 1,309 \\
\hline 7 & 4 & 370 & 358 & 511 & 1,239 \\
\hline 7 & 5 & 370 & 288 & 511 & 1,169 \\
\hline 7 & 6 & 370 & 218 & 511 & 1,099 \\
\hline 7 & 7 & 370 & 148 & 511 & 1,029 \\
\hline 8 & 0 & 370 & 549 & 478 & 1,397 \\
\hline 8 & 1 & 370 & 549 & 534 & 1,453 \\
\hline 8 & 2 & 370 & 549 & 590 & 1,509 \\
\hline 8 & 3 & 370 & 549 & 590 & 1,509 \\
\hline 8 & 4 & 370 & 514 & 590 & 1,474 \\
\hline 8 & 5 & 370 & 444 & 590 & 1,404 \\
\hline 8 & 6 & 370 & 374 & 590 & 1,334 \\
\hline 8 & 7 & 370 & 304 & 590 & 1,264 \\
\hline 8 & 8 & 370 & 234 & 590 & 1,194 \\
\hline 9 & 0 & 370 & 549 & 478 & 1,397 \\
\hline 9 & 1 & 370 & 549 & 534 & 1,453 \\
\hline 9 & 2 & 370 & 549 & 590 & 1,509 \\
\hline 9 & 3 & 370 & 549 & 590 & 1,509 \\
\hline 9 & 4 & 370 & 549 & 590 & 1,509 \\
\hline 9 & 5 & 370 & 514 & 590 & 1,474 \\
\hline 9 & 6 & 370 & 444 & 590 & 1,404 \\
\hline 9 & 7 & 370 & 374 & 590 & 1,334 \\
\hline 9 & 8 & 370 & 304 & 590 & 1,264 \\
\hline 9 & 9 & 370 & 234 & 590 & 1,194 \\
\hline
\end{tabular}


Table 14 Payoff table for $\mathrm{Q}=16$ with Uzbek reservoirs

\begin{tabular}{|c|c|c|c|c|c|}
\hline $\begin{array}{l}\text { Units passed } \\
\text { by player } 1\end{array}$ & $\begin{array}{l}\text { Units passed } \\
\text { by player } 2\end{array}$ & $\begin{array}{l}\text { Player 1's } \\
\text { payoff }\end{array}$ & $\begin{array}{l}\text { Player 2's } \\
\text { payoff }\end{array}$ & $\begin{array}{l}\text { Player 3's } \\
\text { payoff }\end{array}$ & Total payoff \\
\hline 3 & 0 & 333 & 117 & 83 & 533 \\
\hline 3 & 1 & 333 & 117 & 139 & 589 \\
\hline 3 & 2 & 333 & 47 & 195 & 575 \\
\hline 3 & 3 & 333 & -23 & 195 & 505 \\
\hline 4 & 0 & 370 & 183 & 144 & 697 \\
\hline 4 & 1 & 370 & 183 & 200 & 753 \\
\hline 4 & 2 & 370 & 183 & 256 & 809 \\
\hline 4 & 3 & 370 & 113 & 256 & 739 \\
\hline 4 & 4 & 370 & 43 & 256 & 669 \\
\hline 5 & 0 & 370 & 277 & 229 & 876 \\
\hline 5 & 1 & 370 & 277 & 285 & 932 \\
\hline 5 & 2 & 370 & 277 & 341 & 988 \\
\hline 5 & 3 & 370 & 277 & 341 & 988 \\
\hline 5 & 4 & 370 & 207 & 341 & 918 \\
\hline 5 & 5 & 370 & 137 & 341 & 848 \\
\hline 6 & 0 & 370 & 370 & 314 & 1,054 \\
\hline 6 & 1 & 370 & 370 & 370 & 1,110 \\
\hline 6 & 2 & 370 & 370 & 426 & 1,166 \\
\hline 6 & 3 & 370 & 370 & 426 & 1,166 \\
\hline 6 & 4 & 370 & 370 & 426 & 1,166 \\
\hline 6 & 5 & 370 & 300 & 426 & 1,096 \\
\hline 6 & 6 & 370 & 230 & 426 & 1,026 \\
\hline 7 & 0 & 370 & 463 & 399 & 1,232 \\
\hline 7 & 1 & 370 & 463 & 455 & 1,288 \\
\hline 7 & 2 & 370 & 463 & 511 & 1,344 \\
\hline 7 & 3 & 370 & 463 & 511 & 1,344 \\
\hline 7 & 4 & 370 & 463 & 511 & 1,344 \\
\hline 7 & 5 & 370 & 463 & 511 & 1,344 \\
\hline 7 & 6 & 370 & 393 & 511 & 1,274 \\
\hline 7 & 7 & 370 & 323 & 511 & 1,204 \\
\hline 8 & 0 & 370 & 549 & 478 & 1,397 \\
\hline 8 & 1 & 370 & 549 & 534 & 1,453 \\
\hline 8 & 2 & 370 & 549 & 590 & 1,509 \\
\hline 8 & 3 & 370 & 549 & 590 & 1,509 \\
\hline 8 & 4 & 370 & 549 & 590 & 1,509 \\
\hline 8 & 5 & 370 & 549 & 590 & 1,509 \\
\hline 8 & 6 & 370 & 549 & 590 & 1,509 \\
\hline 8 & 7 & 370 & 479 & 590 & 1,439 \\
\hline 8 & 8 & 370 & 409 & 590 & 1,369 \\
\hline 9 & 0 & 370 & 549 & 478 & 1,397 \\
\hline 9 & 1 & 370 & 549 & 534 & 1,45 \\
\hline 9 & 2 & 370 & 549 & 590 & 1,509 \\
\hline 9 & 3 & 370 & 549 & 590 & 1,509 \\
\hline 9 & 4 & 370 & 549 & 590 & 1,509 \\
\hline 9 & 5 & 370 & 549 & 590 & 1,509 \\
\hline 9 & 6 & 370 & 549 & 590 & 1,509 \\
\hline 9 & 7 & 370 & 549 & 590 & 1,509 \\
\hline 9 & 8 & 370 & 479 & 590 & 1,439 \\
\hline 9 & 9 & 370 & 409 & 590 & 1,369 \\
\hline
\end{tabular}




\section{Appendix C: Instructions for the Experiment}

\section{General Information}

We thank you for coming to the experiment. The purpose of this session is to study how people make decisions in a particular situation. During the session it is not permitted to talk or communicate with other participants. If you have a question, please raise your hand and the facilitator will come to your desk to answer it. During the session you will earn money. At the end of the session the amount you have earned will be paid to you in cash. Payments are confidential. We will not inform any of the other participants about the amount you have earned. In the following, all amounts of money are denominated in talers, the experimental currency unit.

The participants in this session are divided into groups of three participants. These groups play completely independently. The composition of the groups remains the same throughout the experiment. You do not know which of the other participants are in your group.

There are three types of players in this game: player 1, player 2, and player 3. Participants play the same role throughout the experiment.

The experiment consists of 24 rounds with the same decision situation. Each round is structured as explained below.

\section{Payoff Structure}

In each round the three players must divide a resource. At the end of each round the players receive a payoff depending on how the resource has been divided. The division of the resource takes place as follows:

Player 1 receives a quantity of the resource. Player 1 can then pass on some quantity of the resource to player 2. After player 2 has received a share of the resource, he or she can pass on some quantity of this share to player 3.

Player 1's payoff from the resource depends on two factors: (1) how much of the resource is available, and (2) how much of the resource is passed on to player 2.

Player 2's payoff depends on the quantity of the resource received from player 1 minus the quantity passed on to player 3 .

Player 3's payoff depends on the quantity of the resource received from player 2.

The payoff of the three players is listed in the enclosed table.

The three player's payoff also depends on the payments they make to each other in exchange for the resources received. This is explained in more detail below.

\section{The Decision Situation}

Each of the 24 rounds consists of two stages. The first stage is the negotiation stage. The second stage is the implementation stage.

\section{The Negotiation Stage}

In the negotiation stage the players can make a non-binding agreement over (1) the division of the resource, and (2) payments they make between each other. This is done in the following steps: 
Step 1: One of the three players is selected to be the proposer. This selection is random and each player is selected to be the proposer with probability one third.

Step 2: The selected player makes a proposal which specifies the following aspects:

- How many units of the resource player 1 passes on to player 2. All integer numbers between three and nine are feasible.

- How many units of the resource player 2 passes on to player 3. Feasible are all integer numbers between zero and the maximum possible (i.e. the number of units passed from player 1 to player 2).

- How many talers player 2 pays to player 1 . All integer numbers from 0 to 1,000 are feasible.

- How many talers player 3 pays to player 2. All integer numbers from 0 to 1,000 are feasible.

Step 3: Each of the two other players (apart from the proposer) decides whether to accept or reject the proposal.

Note that an agreement made in the negotiation stage is not binding. It does not commit the players to act in any particular way at the implementation stage.

The Implementation Stage

In the implementation stage the division of the resource as well as payments between players are implemented. This is done in the following steps:

Step 4: Player 1 decides how many units of the resource to pass on to player 2. This number must be between three and nine (both inclusive).

Step 5: Player 2 decides how many units of the resource to pass on to player 3. Feasible are all integer numbers between zero and the total amount of units received from player 1.

Step 6: Player 2 decides how many talers to pay player 1 . All integer numbers from 0 to 1,000 are feasible.

Step 7: Player 3 decides how many talers to pay player 2. All integer numbers from 0 to 1,000 are feasible.

\section{Phases}

The experiment is divided into of three phases, each consisting of eight rounds. Each round is played exactly the same way as described above. The rounds differ in the quantity of the resource that is available.

The players' payoffs vary with the available quantity of the resource. Therefore a different payoff table is used for each phase. At the outset of a new phase you will be given the relevant payoff table. Please note that the payoff table lists the payoffs of the players excluding the payments made between them.

Payoffs

You start with an initial capital of 1,000 talers. Your payoff from each round will be added to this amount. At the end of the session the talers are converted into Pound Sterling at an exchange rate of $£ 2.50$ per 1,000 talers. The minimum payoff is $£ 3$. 


\section{References}

Abbink K, Sadrieh A (1995) RatImage-research assistance toolbox for computer-aided human behavior experiments. SFB Discussion Paper B-325, University of Bonn

Abbink K, Irlenbusch B, Rockenbach B, Sadrieh A, Selten R (2002) The behavioural approach to the strategic analysis of spectrum auctions: the case of the German DCS-1800 auction. ifo Studien 48:457-480

Abbink K, Jayne T, Moller L (2008) The relevance of a rules-based maize marketing policy: an experimental case study of Zambia, World Bank Policy Research Working Paper 4727

Ambec S, Doucet J (2003) Decentralising hydro power production. Can J Econ 36:587-607

Ambec S, Sprumont Y (2002) Sharing a river. J Econ Theory 107:453-462

Antipova E, Zyranov A, Mckinney D, Savitsky A (2002) Optimisation of Syr Darya water and energy uses. Water Int 27:504-516

Aytemiz L (2001) The optimal joint provision of water for irrigation and hydropower in the Euphrates river: the case of conflict between Turkey and Syria', Ph.D. Dissertation, Oklahoma State University

Barrett S (1994) Conflict and cooperation in managing international water resources. World Bank Policy Research Working Paper 1303, Washington, DC

Berg J, Dickhaut J, McCabe K (1995) Trust, reciprocity and social history. Games Econ Behav 10:122-142

Brandts J, Saijo T, Schram A (2004) How universal is behavior? A four country comparison of spite and cooperation in voluntary contribution mechanisms. Pub Choice 119:381-424

Cameron L, Chaudhuri A, Erkal N, Gangadharan L (2005) Do attitudes towards corruption differ across cultures? Experimental evidence from Australia, India, Indonesia and Singapore. University of Melbourne, Mimeo

Chatterjee B, Howitt R, Sexton R (1998) The optimal joint provision of water for irrigation and hydropower. J Environ Econ Manage 36:295-313

Cox J, Sadiraj K, Sadiraj V (2008) Implications of trust, fear and reciprocity for modeling economic behavior. Exp Econ 11:1-24

Dinar A, Wolf A (1994) International markets for water and the potential for regional cooperation: economic and political perspectives in the western Middle East. Econ Dev Cult Change 43:43-66

Dufwenberg M, Gneezy U (2000) Measuring beliefs in an experimental lost wallet game. Games Econ Behav 30:163-182

Economist Intelligence Unit (2004) Uzbekistan country profile 2004, London, New York and Hong Kong

Fehr E, Kirchsteiger G, Riedl A (1993) Does fairness prevent market clearing? An experimental investigation. Q J Econ 108:437-459

Fershtman C, Gneezy U (2001) Discrimination in a segmented society: an experimental approach. Q J Econ 116:351-377

Gächter S, Falk A (2002) Reputation and reciprocity: consequences for the labour relation. Scand J Econ 104:1-26

Gisser M, Lansford R, Gorman W, Creel B, Evans M (1979) Water trade-offs between electric energy and agriculture in the four corner areas. Water Resour Res 21:529-538

Güth W, Kröger S, Maug E (2008) You may have to do it again, Rocky! — an experimental analysis of bargaining with risky joint profits. New Zealand Economic Papers, forthcoming

Hamilton J, Whittlesey N, Halverson P (1989) Interruptible water markets in the Pacific Northwest. Am J Agric Econ 71:63-75

Herrmann B, Gächter S, Thöni C (2008) Antisocial punishment across societies. Science 319:1362-1367

Houston J, Whittlesey N (1986) Modelling agricultural water markets for hydropower in the Pacific Northwest. West J Agric Econ 11:221-232

International Monetary Fund (2008) Republic of Uzbekistan: 2008 article IV consultation—staff report, Washington, DC

IPPC (Intergovernmental Panel on Climate Change) (2001) Climate change 2001: IPCC third assessment report, http://www.grida.no/climate/ipcc_tar/

Irlenbusch B (2005a) Relying on a man's word? An experiment on non-binding contracts, Int Rev Law Econ, forthcoming

Irlenbusch B (2005b) Are non-binding contracts really not worth the paper? Manage Decis Econ, forthcoming

Khagram S (2004) Dams and development - transnational struggles for water and power. Cornell University Press, Itacha

Kilgour D, Dinar A (2001) Flexible water sharing within an international river basin. Environ Resour Econ 18:43-60

Linn J, Moller L, Kenny S (2005) The natural resource lifeline for Central Asia: water, energy and the environment, chapter 4 in United Nations Development Program (UNDP), Central Asia human develop- 
ment report-bringing down barriers: regional cooperation for human development and human security, Bratislava

McCarl B, Parandvash G (1988) Irrigation development versus hydropower generation: can interruptible irrigation play a role? West J Agric Econ 13:267-276

McCarl B, Ross M (1985) The costs borne by electricity consumers under expanded irrigation from the Columbia River. Water Resour Res 15:233-239

Moller L (2004) Sharing transboundary rivers fairly and efficiently, discussion papers in economics 04/02, University of Nottingham

Moller L (2005a) Transboundary water conflicts over hydropower and irrigation: can multinational development banks help? CREDIT research paper 05/09, University of Nottingham

Moller L (2005b) Sharing transboundary rivers, Ph.D Thesis, University of Nottingham

O'Hara S (2000a) Central Asia's water resources: contemporary and future management issues. Water Resour Dev 16:423-441

O'Hara S (2000b) Lessons from the past: water management in Central Asia. Water Policy 2:365-384

Owen-Thomsen K, Alercon L, Marks D (1982) Agriculture vs. hydropower trade-offs in the operation of the high Aswan Dam. Water Resour Res 18:1605-1613

Rogers P (1997) International river basins: pervasive unidirectional externalities. In: Dasgupta P, Mäler K, Vercelli A (eds) The economics of transnational commons. Clarendon Press, Oxford

Roth A, Prasnikar V, Okuno-Fujiwara M, Zamir S (1991) Bargaining and market behavior in Jerusalem, Ljubljana, Pittsburgh, and Tokyo. Am Econ Rev 81:1068-1095

Selten R (1965) Spieltheoretische Behandlung eines Oligopolmodells mit Nachfrageträgheit. Zeitschrift für die gesamte Staatswissenschaft 121:301-324

Selten R (1975) Reexamination of the perfectness concept for equilibrium points in extensive games. Int J Game Theory 4:25-55

SPECA (2004) Cooperation strategy to promote the rational and efficient use of water and energy resources in Central Asia, United Nations Special Programme for the Economies of Central Asia (SPECA)

US Department of Agriculture (2004) http://www.fas.usda.gov

World Bank (2004a) Water and energy nexus in Central Asia: improving regional cooperation in the Syr Darya Basin, Europe and Central Asia Region, Washington, DC

World Bank (2004b) Central Asia regional electricity export potential study, Europe and Central Asia Region, Washington, DC

World Bank (2004c) Improved water management in the Aral Sea Basin-summary of strategic directions, Europe and Central Asia Region, Washington, DC (mimeo)

World Bank (2004d) World development indicators, www.worldbank.org/data/wdi2004

World Bank (2004e) Uzbekistan at a Glance, http://www.worldbank.org/data/countrydata/aag/uzb_aag.pdf 